MASA In $\mathrm{x}=55646$

\title{
THE IONOSPHERE AT 640 KILOMETERS ON QUIET AND DISTURBED DAYS
}

GPO PRICE $\$$

CFSTI PRICE(S) $\$$

Hard copy (HC)

Microfiche (MF)

f 653 July 65

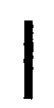

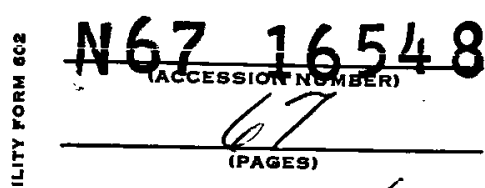
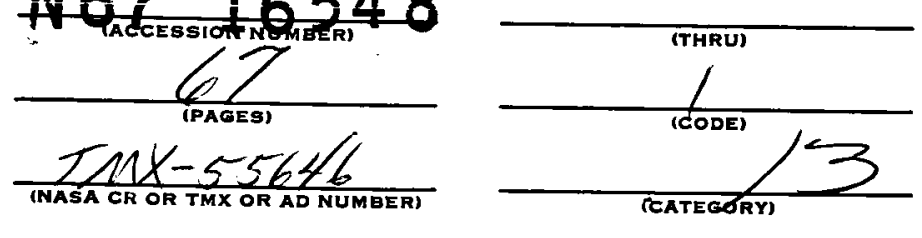

ECEMBER 1966

BY

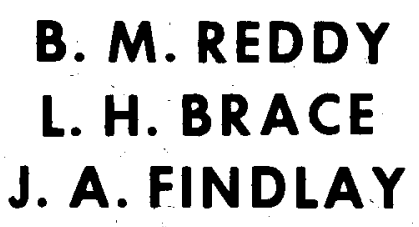

B. M. REDDY

J. A. FINDLAY

$1-$

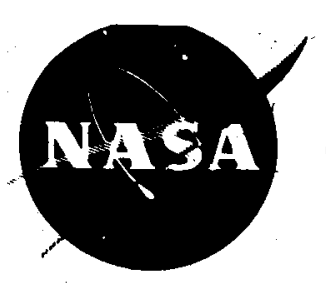

GODDARD SPACE FLIGHT CENTER

GREENBELT, MARYLAND 
$\mathrm{X}-621-66-574$

THE IONOSPHERE AT 640 KILOMETERS

ON QUIET AND DISTURBED DAYS

\author{
by \\ B. M. Reddy \\ L. H. Brace \\ J. A. Findlay
}

December 1966

GODDARD SPACE FLIGHT CENTER

Aeronomy Branch, Goddard Space Flight Center

Greenbelt, Maryland 


\title{
THE IONOSPHERE AT 640 KILOMETERS \\ ON QUIET AND DISTURBED DAYS
}

\author{
B. M. Reddy, L. H. Brace, J. A. Findlay
}

\begin{abstract}
Electrostatic probe measurements of electron concentration $\mathrm{N}_{e}$ from the TIROS-VII satellite are the basis for a study of the global response of the topside ionosphere (640 kilometers) to magnetic disturbances at solar minimum. The quiet-time behavior of $\mathrm{N}_{\mathrm{e}}$ shows many of the features previously evident in Explorer XXII measurements at $1000 \mathrm{~km}$. These are the daytime equatorial maximum, the nighttime mid-latitude maximums and the main trough at the boundary of the polar region. The storm-time response of the ionosphere at 640 $\mathrm{km}$ takes the form of strong $\mathrm{N}_{\mathrm{e}}$ enhancements at middle and high latitudes on the dayside and smaller enhancements on the nightside. This enhancement is in contrast to present thinking which is based on bottomside sounding and total content measurements. At the equator, the storms produce depressions of $\mathrm{N}_{e}$ on the dayside and enhancements on the nightside. Measurements of $\mathrm{N}_{e}$ and electron temperature $T_{e}$ from Explorer XXII show similar but smalle $\mathrm{I}_{\mathrm{e}}$ enhancements during storms, accompanied by slight decreases in $T_{e}$, except in the polar regions where both $\mathrm{N}_{\mathrm{e}}$ and $\mathrm{T}_{\mathrm{e}}$ are increased. It is concluded that the storm-time enhancements of $\mathrm{N}_{\mathrm{e}}$ majy be explained in terms of the observed thermal expansion of the neutral atmosphere which lifts the entire ionosphere, thereby increasing $\mathrm{N}_{e}$ at the fixed altitude of the observations. The different behavior of the equatorial $\mathrm{N}_{\mathrm{e}}$ is consistent with electrodynamic drift theory. The storm-time increase of $T_{e}$ in the polar region may result from additional heating, while the
\end{abstract}


decrease of $\mathrm{T}_{e}$ at all other latitudes is caused by both increased collisional cooling to the expanded neutral atmosphere and by a decrease in the escape flux of photoelectrons which heat the upper F-region. 


\section{THE IONOSPHERE AT 640 KILOMETERS \\ ON QUIET AND DISTURBED DAYS}

\section{INTRODUCTION}

The TIROS VII satellite was launched on June 19, 1963 into a nearly circular orbit having perigee and apogee altitudes of $625 \mathrm{~km}$ and $660 \mathrm{~km}$ respectively and an inclination of $58^{\circ}$. It carried an electrostatic Langmuir probe of the cylindrical type designed for the insitu measurements of electron concentration $\mathrm{N}_{\mathrm{e}}$ and temperature $T_{e}$. It carried on board a tape recorder providing data from a complete orbit upon interrogation. The low telemetry rate provided by the tape recorder has made extensive analysis of data for $T_{e}$ impractical, therefore only $\mathrm{N}_{e}$ data are presented here. The nearly constant altitude of the satellite permitted resolution of the local time and latitudinal variations of the ionosphere. The purpose of this paper is to (i) present the measurements of electron concentration made during the first three weeks after the launch when full orbit coverage was obtained, (ii) compare these $640 \mathrm{~km}$ data with measurements made at $1000 \mathrm{~km}$ on Explorer XXII (Brace, Reddy and Mayr 1967) by the same iechnique and (iii) describe the effects of several magnetic disturbances on the global distribution of electrons at $640 \mathrm{~km}$.

\section{THE EXPERIMENT}

The cylindrical probe is a sensor that has been employed on several rockets and satellites, and the experimental details have been described elsewhere 
(Brace et al., 1956; Spencer et al., 1965). In the TIROS-VII application, the cylindrical collector, $23 \mathrm{~cm}$ long and $.057 \mathrm{~cm}$ in diameter, was mounted so as to extend outward from the satellite which serves as the reference body. A sawtooth voltage was applied to the probe and the resulting volt-ampere curves were analyzed in terms of the plasma density. Figure 1 illustrates the basic experimental set up. The electron concentration $\mathrm{N}_{e}$ is derived from the electron saturation region of the curve (when the probe is driven positive with respect to plasma) by using the relation (Spencer et al., 1965)

$$
N_{e}=\frac{\pi I_{e}}{A e\left(2 e V / m_{e}\right)^{1 / 2}} \text { provided }\left|\frac{e V}{k T_{e}}\right|>1
$$

where $e$ is the electronic change, $k$ is the Boltzmann constant. $I_{e}$ is the electron current, $\mathrm{m}_{\mathrm{e}}$ is the electron mass, $\mathrm{A}$ is the area of the collector and $\mathrm{V}$ is the potential of the probe relative to the plasma.

The satellite spins about its axis at a rate of approximately $5 \mathrm{rpm}$; and about 6 current characteristics are recorded per each satellite rotation. Further details of the experiment may be found in the Appendix.

\section{QUIET IONOSPHERE RESULTS}

Owing to the nearly circular orbit and the concentration of the data in a three week period in midsummer, altitude and seasonal changes are not significant variables in the experimental results to be discussed here. The major variables 


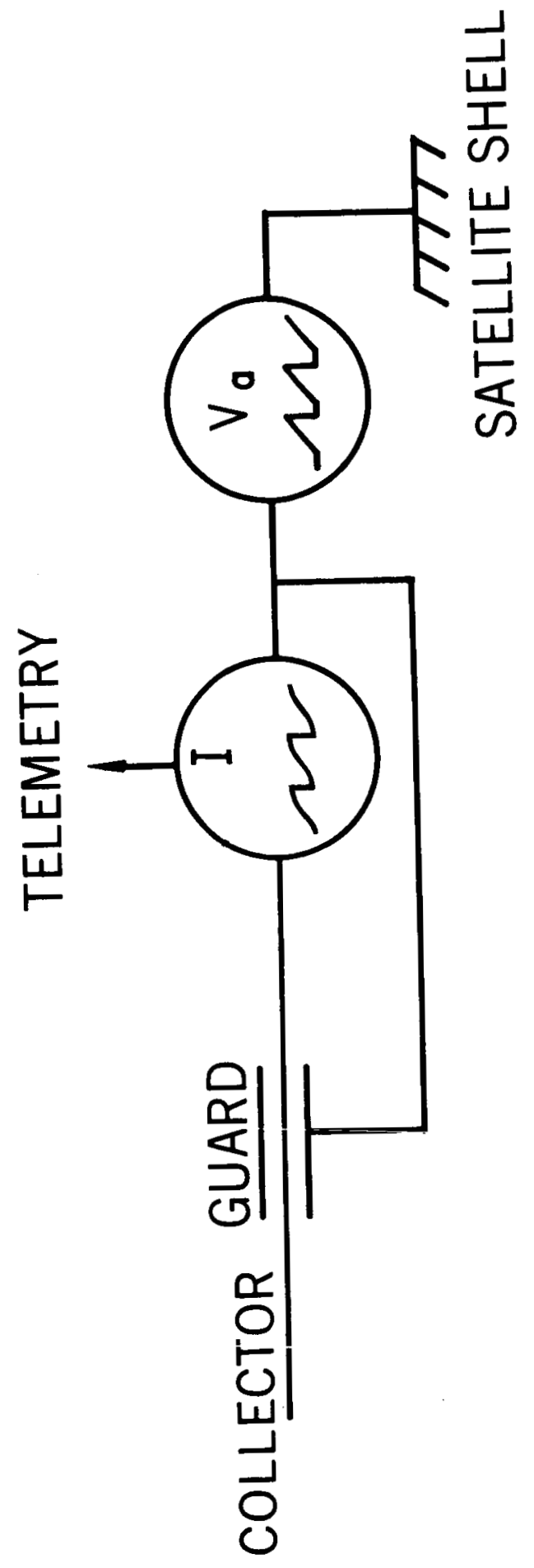

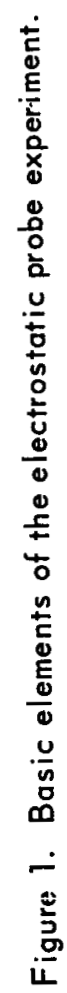


to be separated in the data are the latitude, longitude and local time effects. This has been accomplished by limiting our consideration to the three hour periods following local noon and local midnight and plotting the measurements from three broad longitude bands as a function of latitude. During this period, the solar $2800 \mathrm{Mcs}$ flux, which is taken to be the indicator of the solar extreme ultraviolet, varied from 72 to $79\left[10^{-22} \mathrm{~W} / \mathrm{m}^{2} \mathrm{c} / \mathrm{s}\right]$. The data discussed in the immediately following section concerns only magnetically quiet periods when $a_{p} \leq 9$. The data for the magnetically active periods is presented and discussed in a later section.

\section{Raw Data}

Figure 2 shows a plot of the electron concentration for the afternoon period between 1200 and 1530 hours local time. The consecutive points from the same orbit are joined by straight lines to approximate the instantaneous latitudinal structure. Although the measurement resolution was great enough to provide a data point for every degree of latitude, data corresponding to this resolution was employed only when sharp changes occurred. Data points lying in the longitude range of +50 to -50 (hereafter referred to as European longitudes) are connected by solid lines, and those between -50 and -150 (American longitudes) are connected by long dashes. The passes connected by short dashed lines represent all other longitudes (Asian longitudes). The latter region could not be further subdivided because of scarcity of recorded passes in those longitudes within the selected local time periods. Figure 3 is a similar plot for the nighttime period 


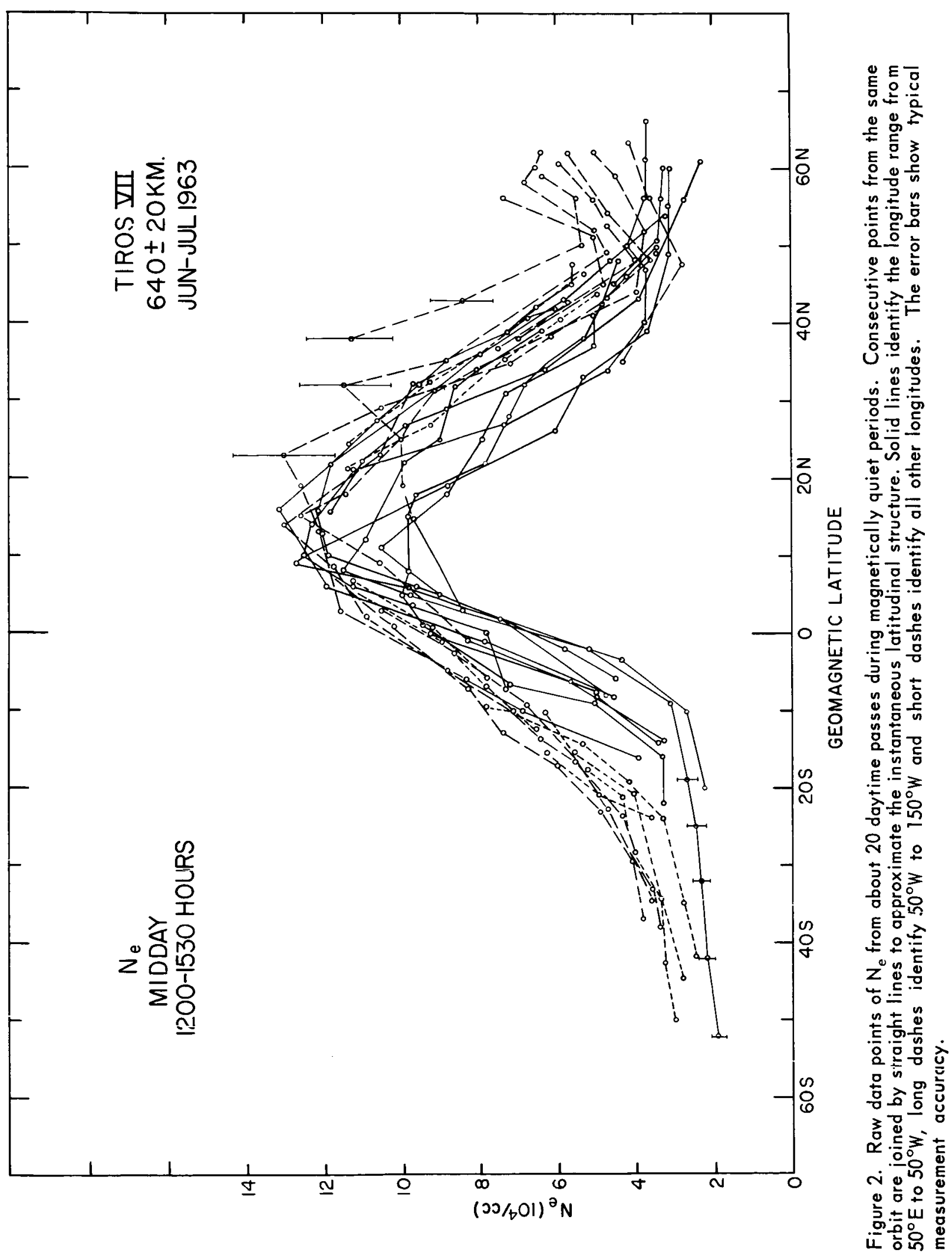




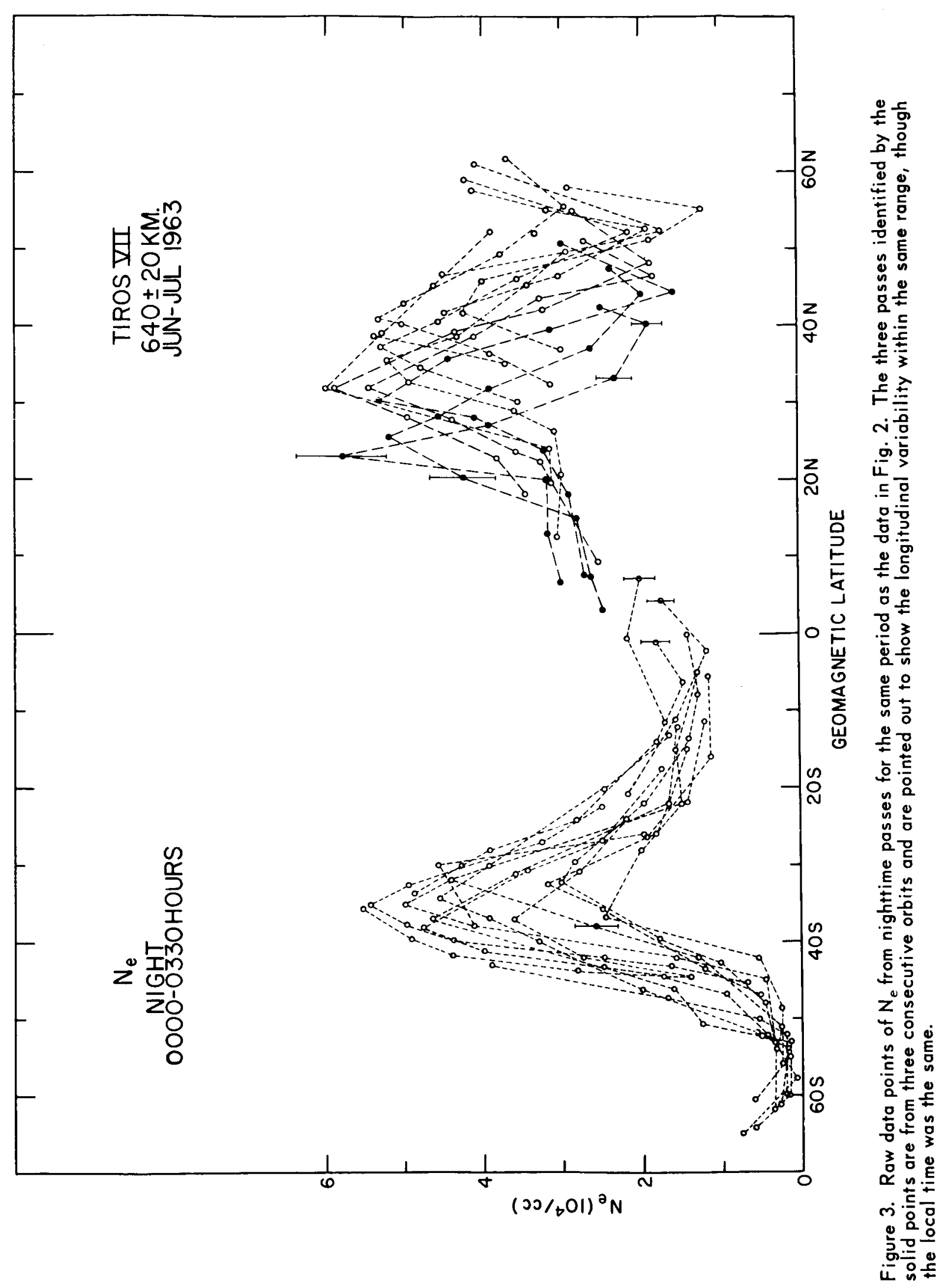


between 0000 and 0330 hours local time. The points shown in Figures 2 and 3 represent only a part of the data available for the three week period, though all the available data falls within the limits indicated in these plots. These figures are intended to show the trend and the variability of the structure without too much crowding of data points.

\section{$\underline{\text { Averaged Data }}$}

Figures 4 and 5 show the outlines of the essential extremes of $\mathrm{N}_{e}$ derived from plots such as shown in Figures 2 and 3. These are provided to aid in showing the average latitudinal structure and the longitudinal variability more clearly. Figure 6 is a summary of all the quiet time data during the local midday and night periods averaged for all the longitudes.

\section{DISCUSSION OF QUIET DATA}

\section{The Latitudinal Structure*}

The most obvious features in the latitudinal structure (Figure 6) are the miduay equatorial maximum and the nighttime equatorial minimum. This nighttime equatorial trough is flanked by two maximums on either side at about $35^{\circ}$ north and south. These features are very similar to those found near $1000 \mathrm{~km}$ in the Explorer XXII electrostatic probe data (Brace and Ready, 19̂ôj). The tô̄side sounder measurements (Lockwood and Nelms, 1964) and the Ariel measurements (Sayers, 1964) also indicate these gross features.

\footnotetext{
* all latitude references are geomagnetic.
} 


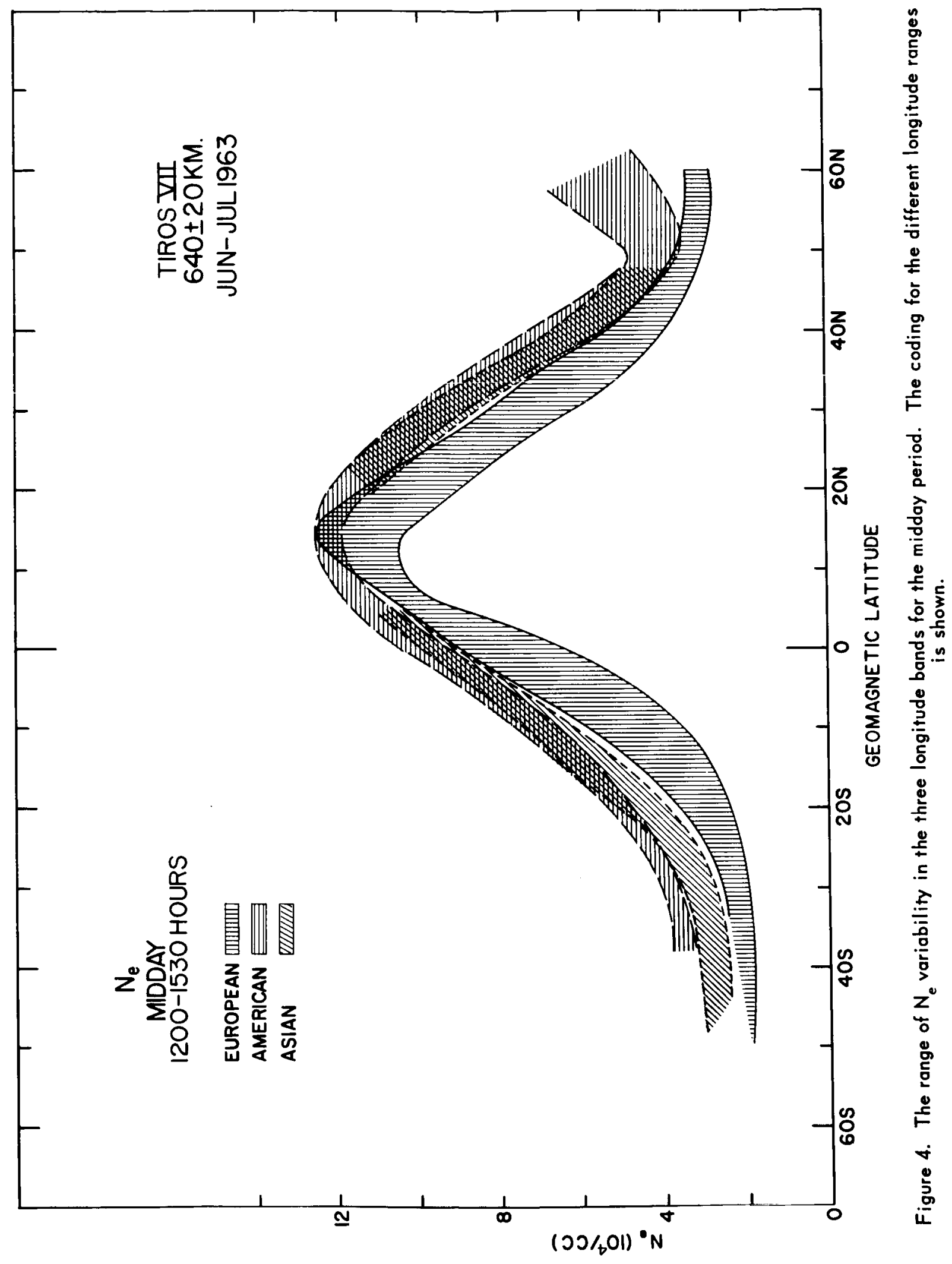




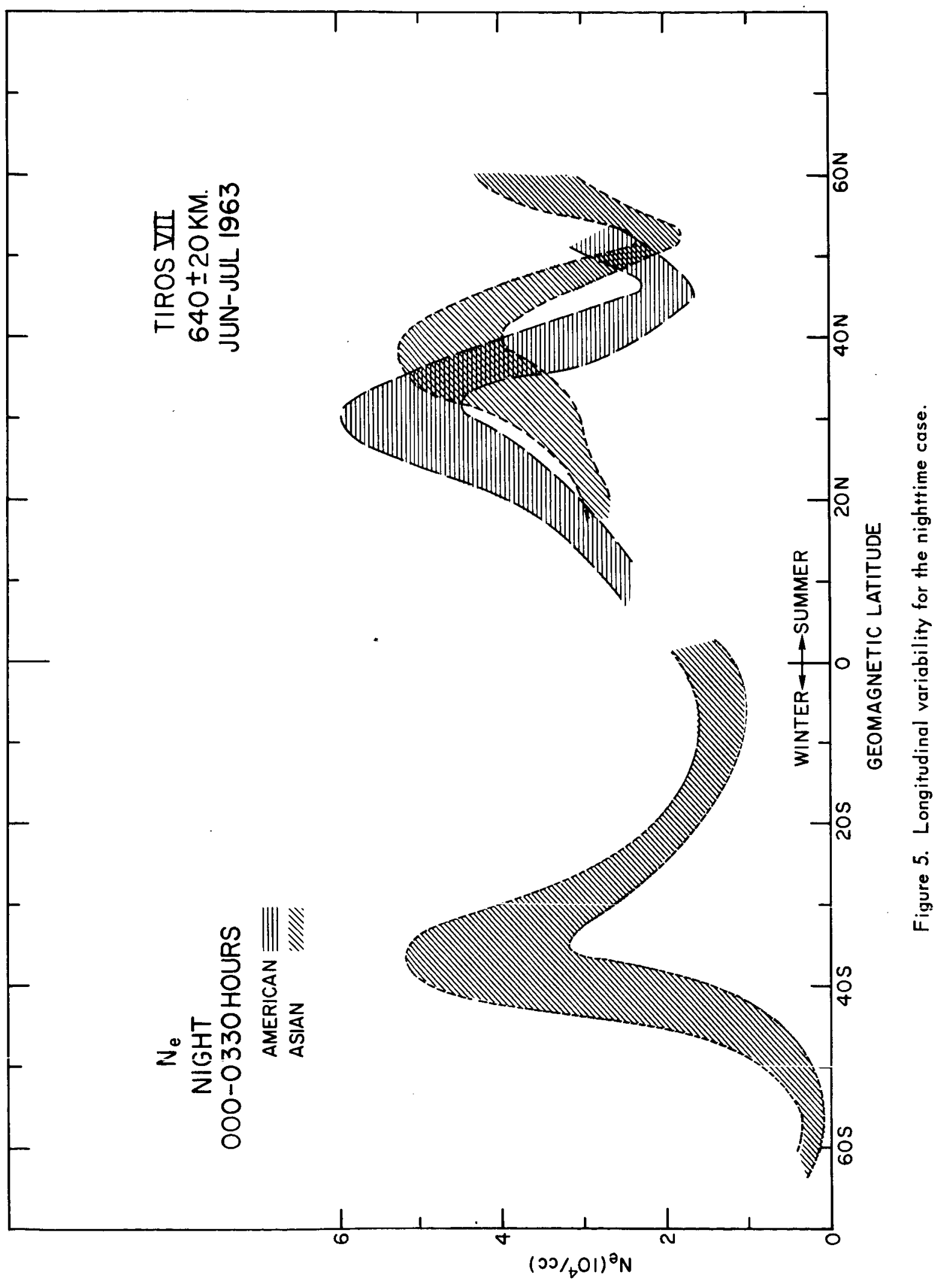




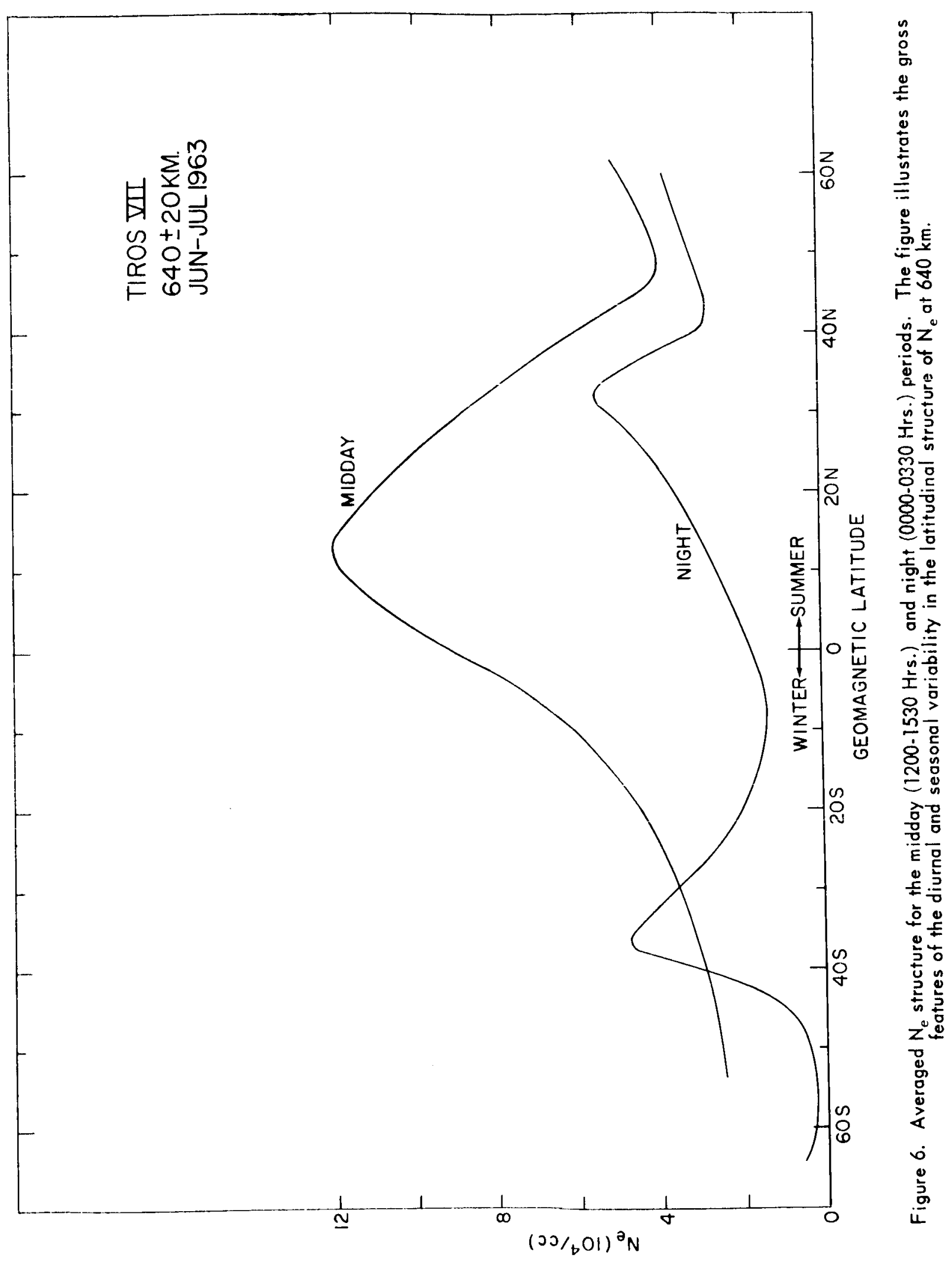


The trough of $\mathrm{N}_{\mathrm{e}}$ which is observed near $50^{\circ}$ (Figure 6) seems to behave like the "main trough" reported by Muldrew (1965) from Alouette I observations of $f_{x} F_{2}$. Owing to the $12^{\circ}$ tilt of the magnetic axis the $58^{\circ}$ inclination of the TIROS VII orbit does not permit the northern trough to be reached at European longitudes nor its southern counterpart at American longitudes. Therefore a global comparison of the Alouette and TIROS trough observations is not feasible. It appears that the most significant difference in the trough at $640 \mathrm{~km}$ and at the $\mathrm{F}_{2}$ maximum is its disappearance at midday at the lower altitude. This filling-in of the trough may result from local production at the lower altitudes. A more detailed study of the trough behavior, employing the full spatial resolution of the experiment, will be presented in a later paper.

\section{Longitudinal Effects on the Latitude Structure}

The variation of $\mathrm{N}_{\mathrm{e}}$ that is seen in any particular longitude range (Figures 4 and 5) is caused by the longitude variations within the stated range. A close look at the data clearly indicates that the local time variations within the stated range are not as great as the longitude variations within each range. This is best illustrated in Figure 3, where the latitudinal behavior in the northern hemisphere shows considerable variability in $\mathrm{N}_{e}$ in the three successive passes on the same day which are identified by solid points. These passes differed in longitude by about $24^{\circ}$, but did not differ significantly in local time. The latitudes at which the ionization peaks and troughs are observed within each orbit also 
exhibit a longitudinal control. Another longitudinal difference is obvious in the midday data shown in Figure 4, where the electron concentration is considerably lower for the European longitudes - a result which is consistent with the measurements reported by Sayers (1964).

\section{Diurnal and Seasonal Variations}

In addition to variability with latitude and longitude, the ionosphere at $640 \mathrm{~km}$ uninergues remarkable diurnai and seasonal variations. The electron concentration at the equator decreases by a factor of 6 to 8 from day to night. At middle latitudes the diurnal variation is much smaller. The daytime $\mathrm{N}_{\mathrm{e}}$ exceeds the nighttime $\mathrm{N}_{e}$ in the summer hemisphere and vice versa in the winter hemisphere (Figure 6). $\mathrm{N}_{\mathrm{e}}$ increases both day and night approaching the summer pole and decreases toward the winter pole. For example, nighttime electron concentrations of $1 \times 10^{3} / \mathrm{cc}$ were common between $50^{\circ}$ and $60^{\circ}$ in the winter hemisphere whereas the summer hemisphere values for similar latitudes were above $3 \times 10^{4} / \mathrm{cc}$.

The equatorial maximum in $\mathrm{N}_{e}$ is shifted toward the sub-solar latitude (Figure 6) and the general level of ionization is considerably higher in the summer hemisphere than in the winter hemisphere at any latitude. However this does not appear to be a simple zenith angle control as can be seen in Figure 4. At the American longitudes, the noon solar zenith angle was as much as $35^{\circ}$ north of the geomagnetic equator while it was only $12^{\circ}$ north at the Asian longitudes, 
and $20^{\circ}$ north at the European longitudes. Yet, the geomagnetic latitudes of the midday maximums do not differ by more than a few degrees from each other for these three longitude ranges.

Comparison with other satellite results

As mentioned earlier, various aspects of the global ionospheric structure have been evident also in the Ariel results reported by Willmore and Henderson (1965), by Sayers (1964), and the Alouette I results reported by Lockwood and Nelms (1964).

An attempt was made to compare TIROS VII results with the Alouette I results derived from an entirely different measuring technique, but at essentially the same time. Figure 7 shows this comparison between the TIROS VII afternoon $\mathrm{N}_{\mathrm{e}}$ values at $640 \mathrm{~km}$ and the Alouette $\mathrm{I}$ afternoon $\mathrm{N}_{\mathrm{e}}$ values at $650 \mathrm{~km}$ (Chan et al., 1966). The agreement is very good in view of the fact that the measurements were not actually simultaneous.

It is most instructive to compare the TIROS VII results with results from Explorer XXII satellite obtained with the same measuring technique. The orbit of Explorer XXII was nearly circular at $1000 \mathrm{~km}$ and the results from a similar season, local time and solar activity as of TIROS VII were chosen for the comparison. Figures 8 and 9 show this comparison between the TIROS and Explorer XXII $\mathrm{N}_{\mathrm{e}}$ results for the daytime and nighttime respectively. As noted earlier the 


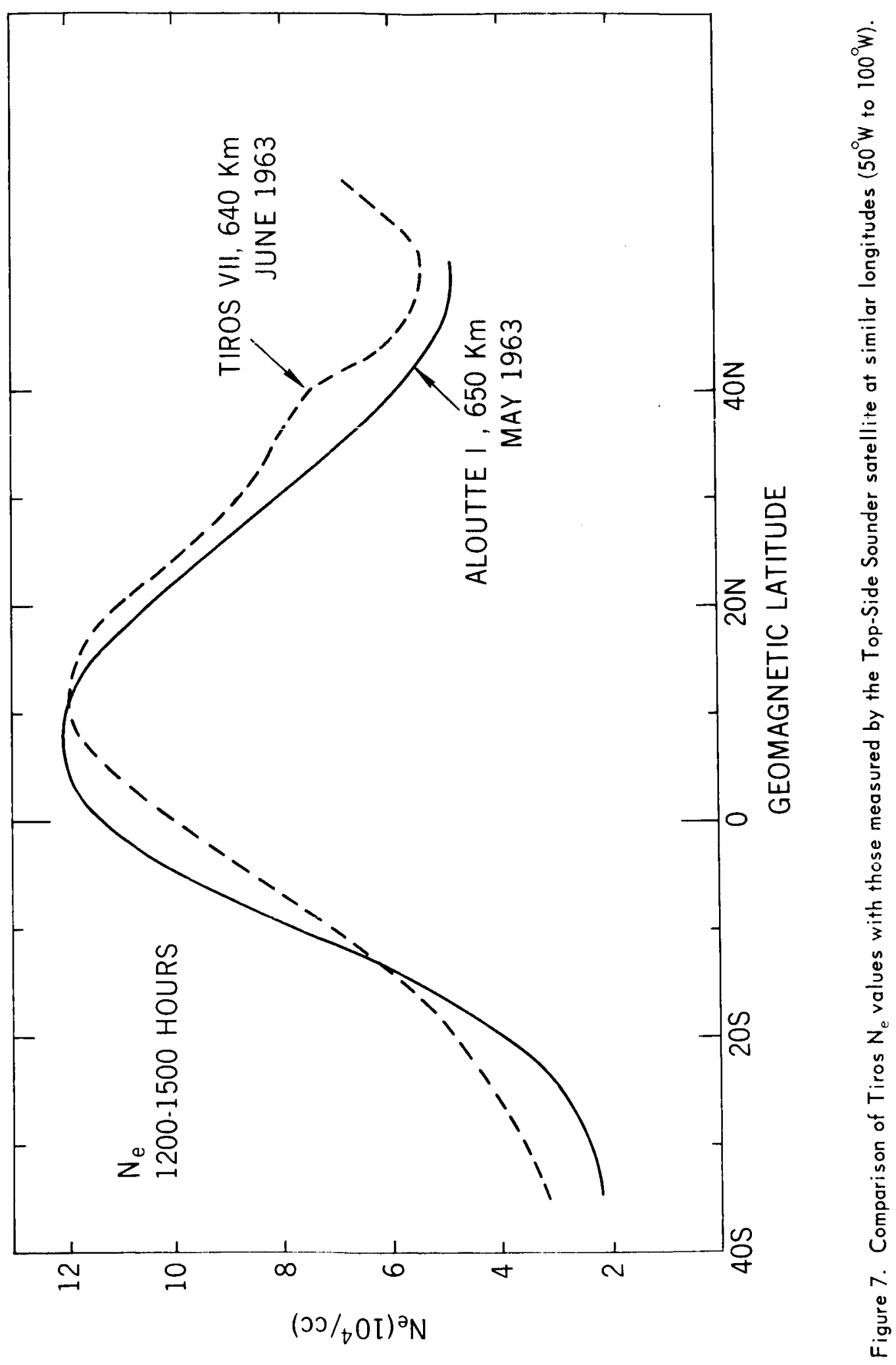




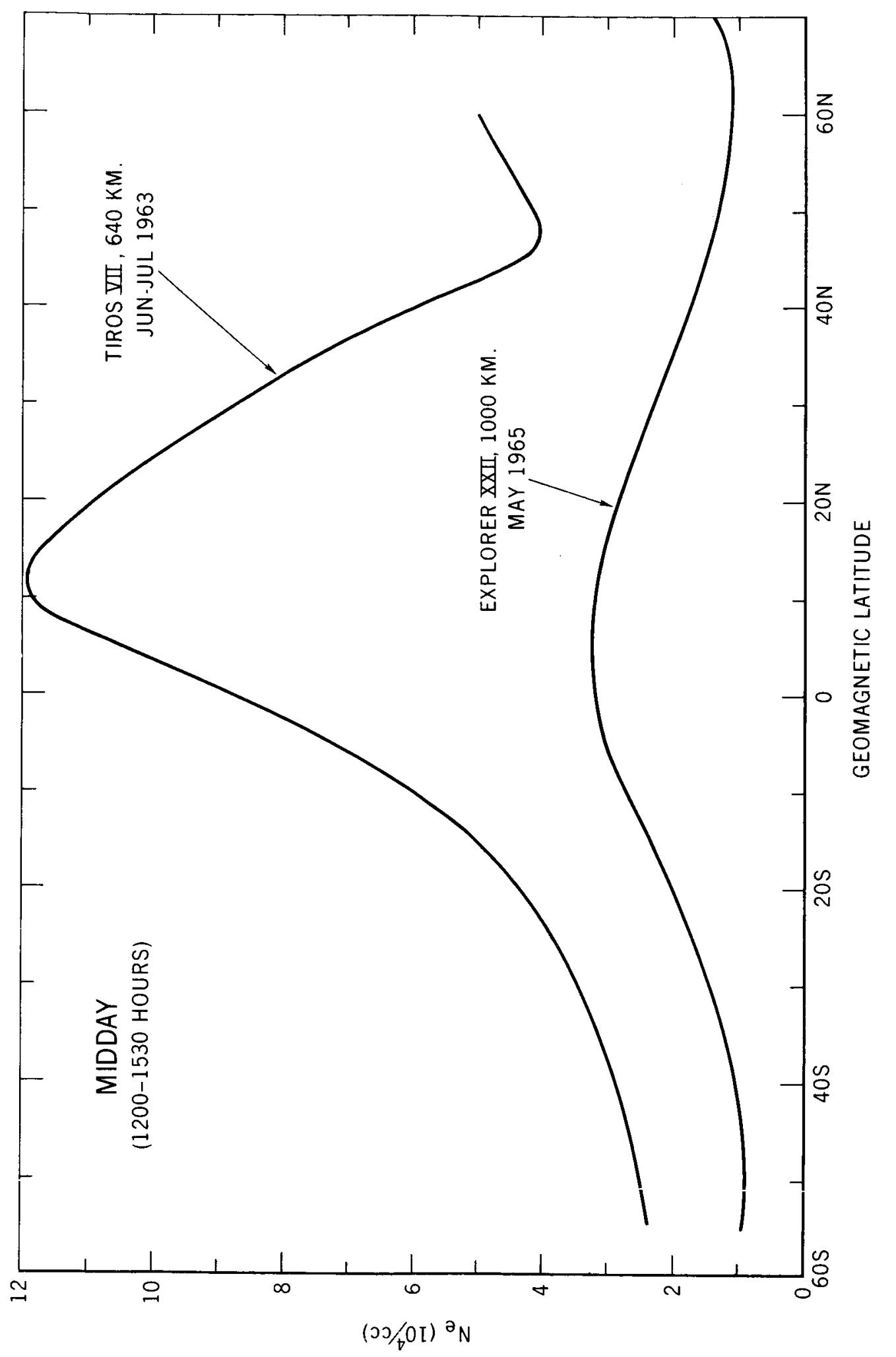

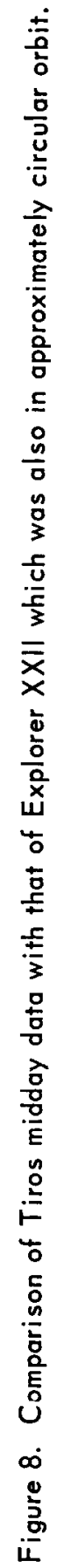




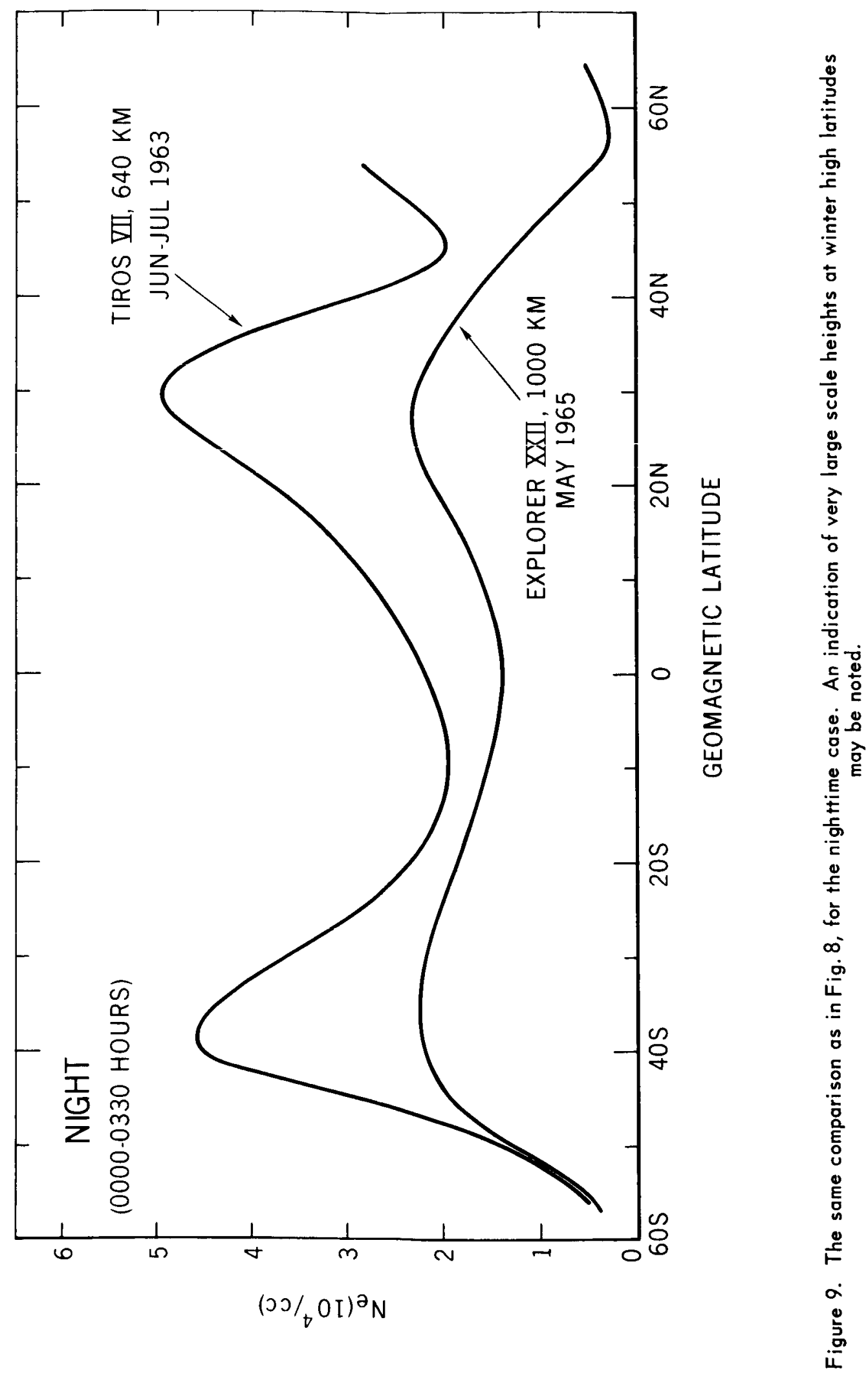


midday equatorial maximum at $640 \mathrm{~km}$ is shifted towards the summer hemisphere whereas at $1000 \mathrm{~km}$ the maximum is nearly at the magnetic equator. The nighttime trough however is somewhat more symmetrical about the equator at both altitudes. Perhaps the most striking similarity between the TIROS and Explorer results is the existence of nighttime maximums at mid-latitudes with a steep decrease poleward. It is evident in Figures 8 and 9 that the diurnal variations of the electron concentration are smaller at $1000 \mathrm{~km}$ than at $640 \mathrm{~km}$, and this is especially true in the nighttime collapse of the equatorial ionization.

Now that the night time double maximums and the equatorial trough in the latitudinal plot of $\mathrm{N}_{e}$ have been identified as definite features of the topside ionosphere at different levels, these features deserve a closer examination. Brace, Reddy and Mayr (1967) have examined this night time trough at $1000 \mathrm{~km}$ and have found that the observed latitudinal distribution of $\mathrm{N}_{e}$ and $\mathrm{T}_{e}$ near the equator are consistent with diffusive equilibrium. In a paper to be published on the ion composition and temperature in the topside ionosphere (Mayr, Brace and Dunham, 1966), the latitudinal $\mathrm{N}_{\mathrm{e}}$ distributions derived from TIROS VII and Explorer XXII are found to be consistent with each other.

Hanson and Patterson (1964) have suggested that a veriical drifit of iônization during night time might be responsible for the night-time maintenance of the mid-latitude F-region. Further King and Kohl (1965) and Kohl and King (1966) have described an atmospheric wind system that would induce such ionospheric 
drifts at middle latitudes having a downward component during day and an upward component during night. These drifts are in the correct sense to contribute to the observed enhancements at night.

We will present in the following section some storm time measurements from TIROS VII and Explorer XXII and discuss their implications.

\section{DISTURBED IONOSPHERE RESULTS}

The circular nature of the orbit and the full orbit coverage provided by the on-board tape recorder made the TIROS VII satellite a particularly useful platform for some very specialized ionospheric studies. In particular, the global response of the ionosphere to short term perturbations such as magnetic disturbances could be studied in great detail as the nearly constant altitude of the satellite permitted the purely geographical structure and its perturbations to be accurately resolved.

\section{Dayside}

Three different sets of observations on a few magnetically disturbed days in July 1963 are presented here. The period from July 4th through 9th was generally disturbed, but three relatively distinct events could be recognized. The identification of these events as separate will be better appreciated after examining the results. The values of the planetary three-hour-range indices $\left(\mathrm{K}_{\mathrm{p}}\right)$ and the corresponding equivalent planetary amplitudes $\left(a_{p}\right)$ are given in Table I for the relevant days. 
TABLE I

\begin{tabular}{|c|c|c|c|c|c|c|c|c|c|c|c|c|c|c|c|c|c|}
\hline \multicolumn{9}{|c|}{ July 4th } & \multicolumn{9}{|c|}{ July 5th } \\
\hline$K_{p}$ & $0_{+}$ & $1_{+}$ & 2 o & 2 & 3 。 & 3 。 & & $4+$ & $3_{+}$ & $4_{+}$ & 4. & 2 。 & 2 o & & 2 & 4 & 4 \\
\hline \multirow[t]{2}{*}{$a_{p}$} & 2 & 5 & 7 & 6 & 15 & 15 & 27 & 32 & 18 & 32 & 27 & 7 & 7 & 6 & 3 & 22 & 22 \\
\hline & \multicolumn{8}{|c|}{ July 6th } & \multicolumn{9}{|c|}{ July 7 th } \\
\hline $\mathrm{K}_{\mathrm{p}}$ & 3 。 & 6 & 5 & 3 & 2 。 & $2_{+}$ & $2+$ & $1_{+}$ & 2 & $2+$ & 3 & 3 。 & $3_{+}$ & 3 & & 2 & 2 。 \\
\hline$a_{p}$ & 15 & 67 & 39 & 12 & 7 & 9 & 9 & 5 & 7 & 9 & 12 & 15 & 18 & 15 & & 6 & 7 \\
\hline \multicolumn{9}{|c|}{ July 8th } & \multicolumn{9}{|c|}{ July 9th } \\
\hline $\mathrm{K}_{\mathrm{p}}$ & 3 o & 2 & 4 & 2 & $2_{+}$ & 3 & $2+$ & 4 & 4. & 4 & 3 & $3_{2}$ & $2+$ & 2 & & ${ }^{2}+$ & 3 。 \\
\hline$a_{p}$ & 15 & 9 & 22 & 6 & 9 & 12 & 9 & 22 & 27 & 22 & 18 & 12 & 9 & 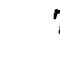 & 7 & 9 & 15 \\
\hline & & & & & & & & & & & & & & & & & \\
\hline
\end{tabular}

The planetary three-hour-range indices $\left(\mathrm{K}_{\mathrm{p}}\right)$ and the equivalent planetary amplitudes $\left(a_{p}\right)$ for the period of study. 


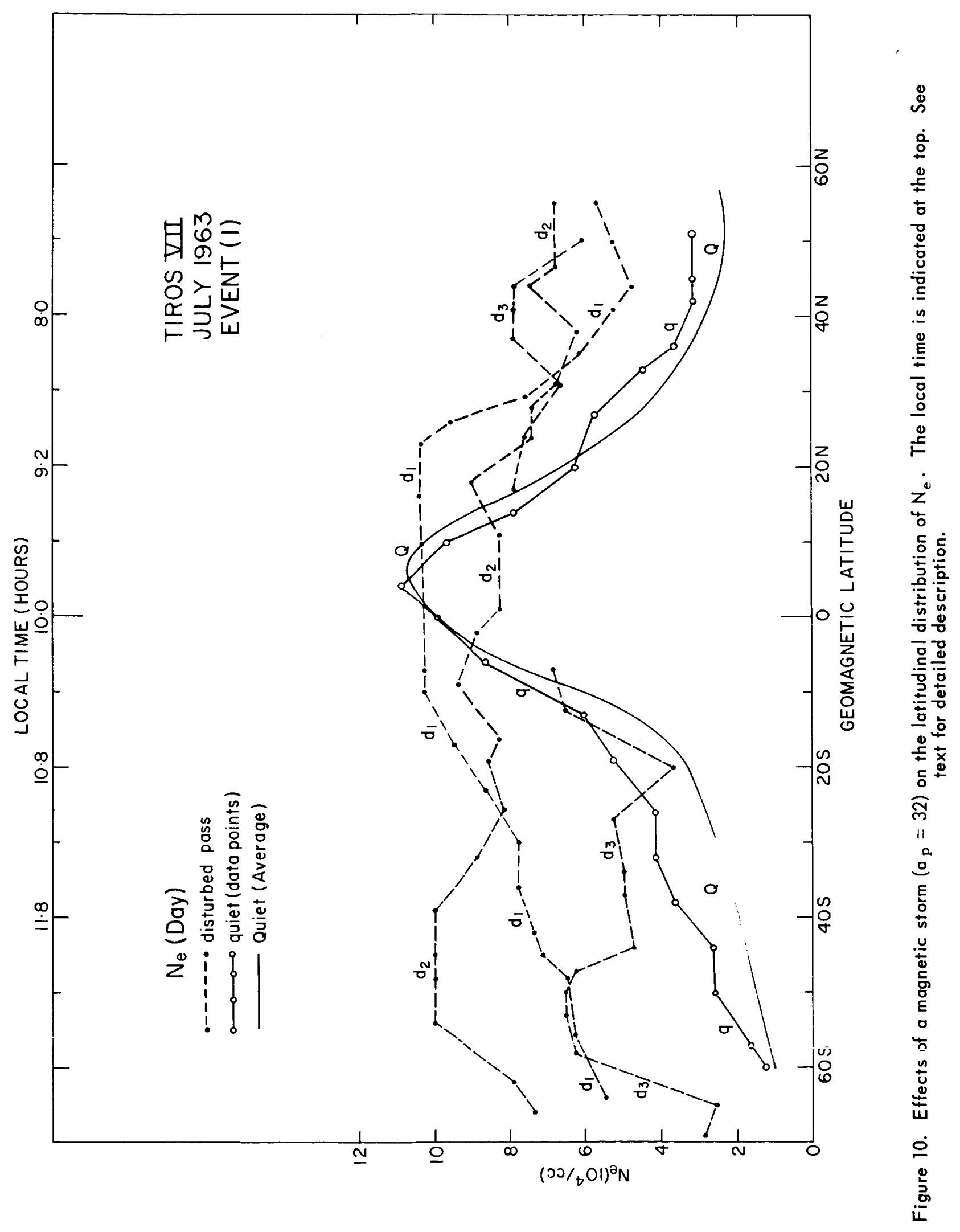




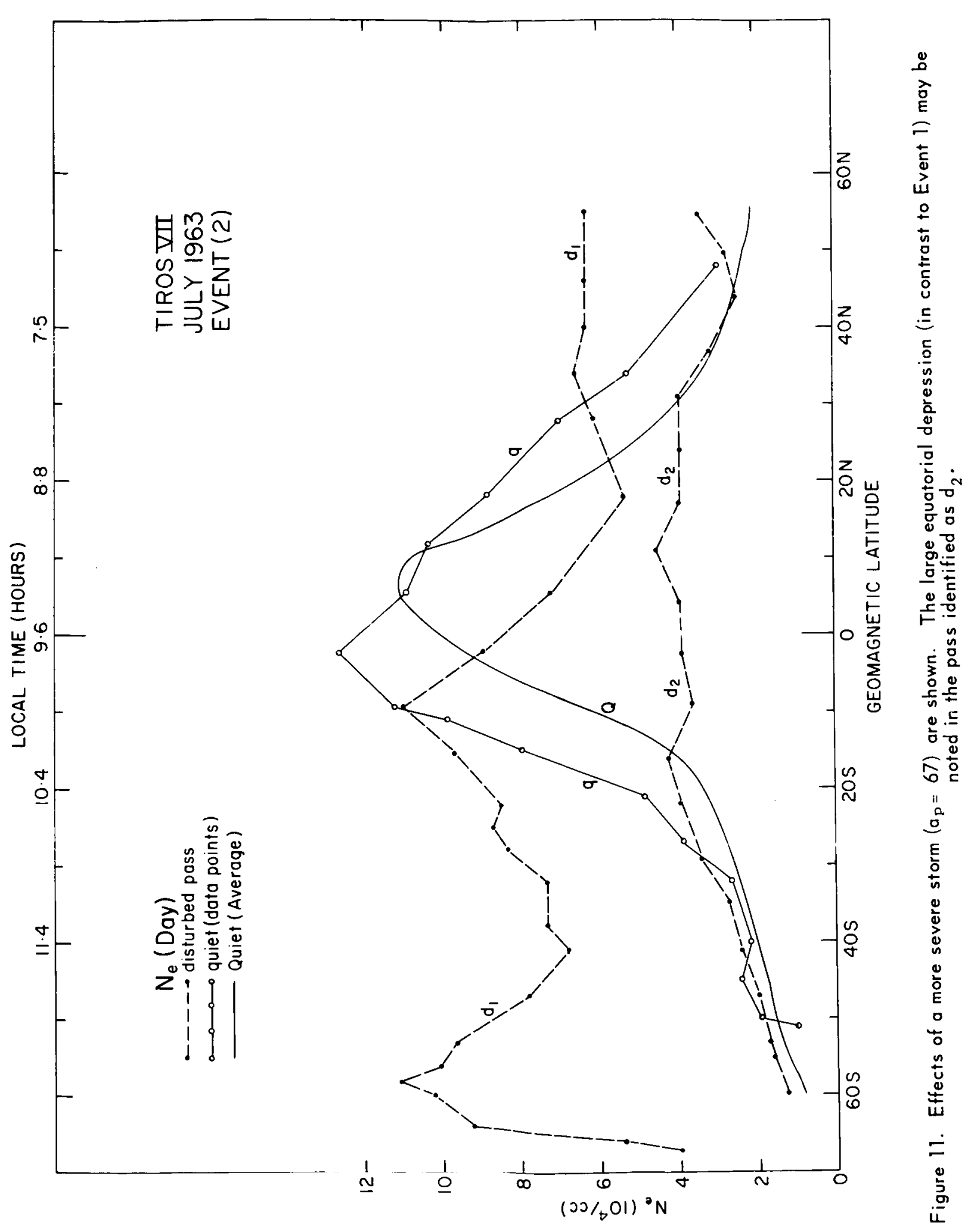


the fourth three-hour period of the day when the storm was almost over. The plot marked $\mathrm{q}$ is a quiet pass starting around 1500 hours G.M.T. on the same day, and the smooth curve (marked Q) represents the averaged data for quiet days.

Figure 12 depicts event (3) where the broken curve $d$ represents a pass in the morning of July 9th following disturbed conditions when $\mathrm{K}_{\mathrm{p}}$ reached a value of $4_{0}\left(a_{p}=27\right)$. This is the mildest of the three events reported here. The plots marked $q_{1}$ and $q_{2}$ represent relatively quiet conditions at 1400 GMT on July 8th and at 1100 GMT on July 9 th respectively, while $Q$ represents the corresponding averaged quiet condition.

Returning to event ( 1 ) for closer examination, $d_{1}, d_{2}$ and $d_{3}$ represent three consecutive passes beginning at the peak of the disturbance. At first the electron concentration increases at almost all latitudes $\left(d_{1}\right)$, but 90 minutes later during the next pass $\left(d_{2}\right)$ increase is much greater at latitudes greater than $30^{\circ}$, especially in the winter hemisphere. At lower latitudes, the increase is very subdued, in fact there is a reduction in the electron concentration in the immediate vicinity of the equator. The results of the next pass $\left(d_{3}\right)$ show a trend to return back to normalcy. The later pass in the afternoon (marked q) shows that the ionosphere at this level has almost completely recovered and is very close to the curve $\mathrm{Q}$ representing the average quiet behavior.

Event (2), which is a more intense disturbance, was similar to event (1) during its first phase as shown by pass $d_{1}$; but during pass $d_{2}$ the depression 


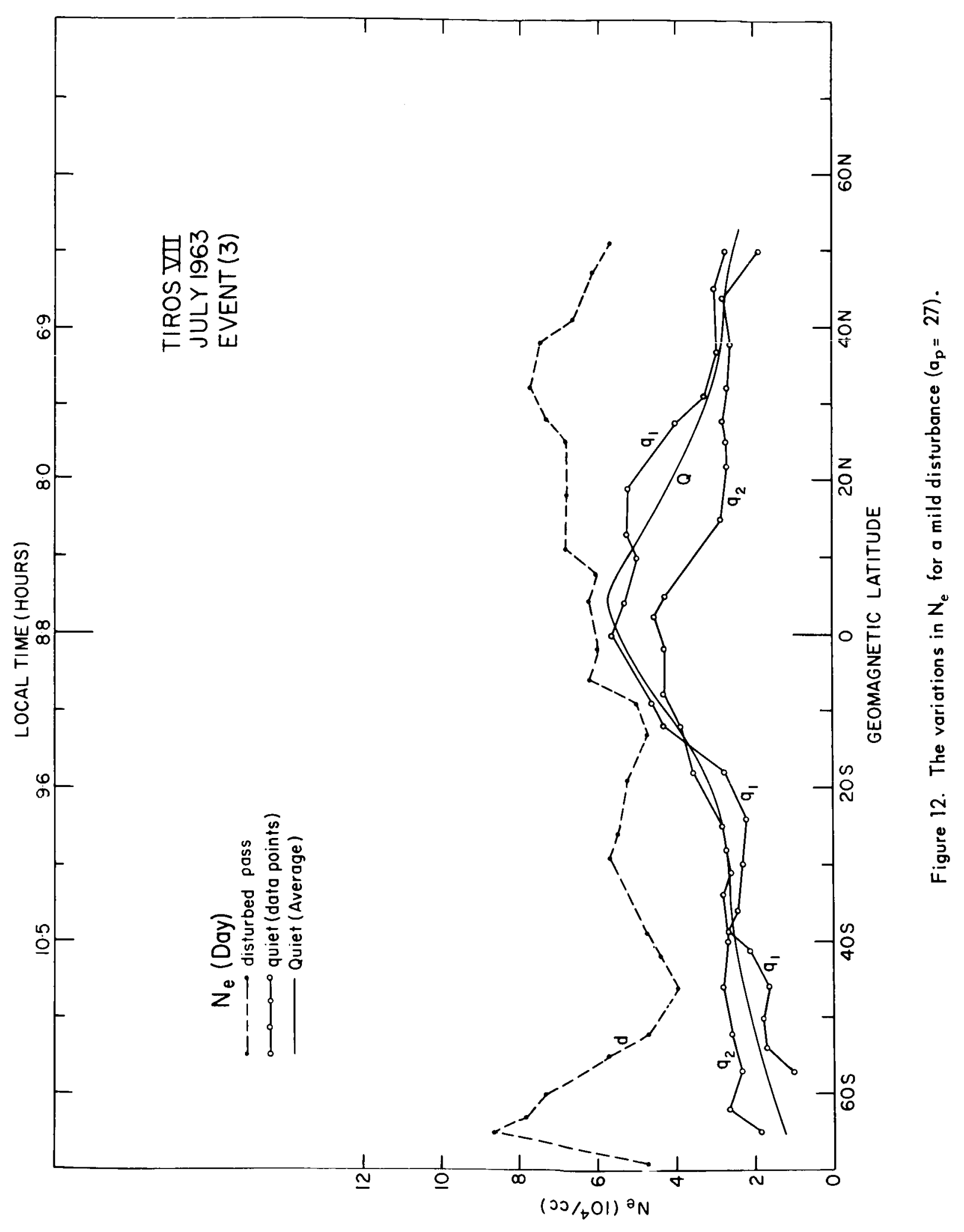


of ionization at the equator was much greater than for event (1). After the storm (q) the ionization exceeded the typical quiet-day value at mid-latitudes. The results of event (3) are similar to the other events except that there was no equatorial depression, in fact a slight increase was observed. For the three storms reported here, the average time delay between the peak magnetic activity and the maximum $\mathrm{N}_{\mathrm{e}}$ enhancement was less than two hours.

It is interesting to note here that during event (3) when the equatorial crossing occurred at 0845 hours local time, the quiet-day equatorial peak was very low, whereas in event (2), it is already well developed when the local time was later by only an hour. This reflects the rapid build up of the equatorial maximum.

For a clearer view of the effect of the magnetic storms on the electron concentration, the radio of disturbed $\mathrm{N}_{\mathrm{e}}$ to quiet $\mathrm{N}_{\mathrm{e}}$ plotted against latitude for all the three events is shown in Figure 13. The disturbed values $\left(\mathrm{N}_{e}\right) d$, correspond to the most disturbed passes. The quiet values $\left(\mathrm{N}_{\mathrm{e}}\right)_{\mathrm{Q}}$ are from the averaged smooth curve representing the quiet-day distribution.

Some interesting observations can be made from Figure 13. The ratio $\left(\mathrm{N}_{\mathrm{e}}\right)_{\mathrm{d}} /\left(\mathrm{N}_{\mathrm{e}}\right)_{\mathrm{Q}}$ is greatest at high latitudes in the winter hemisphere and appears to vary directly with the magnitude of the $a_{p}$ index. While there is a slight increase in the equatorial electron concentration during a mild disturbance (event 3), a general depression of ionization occurs at the equator when the severity of the storm increases (events 1 and 2). The increase of $\left(\mathrm{N}_{e}\right)_{d} /\left(\mathrm{N}_{e}\right)_{Q}$ with latitude 


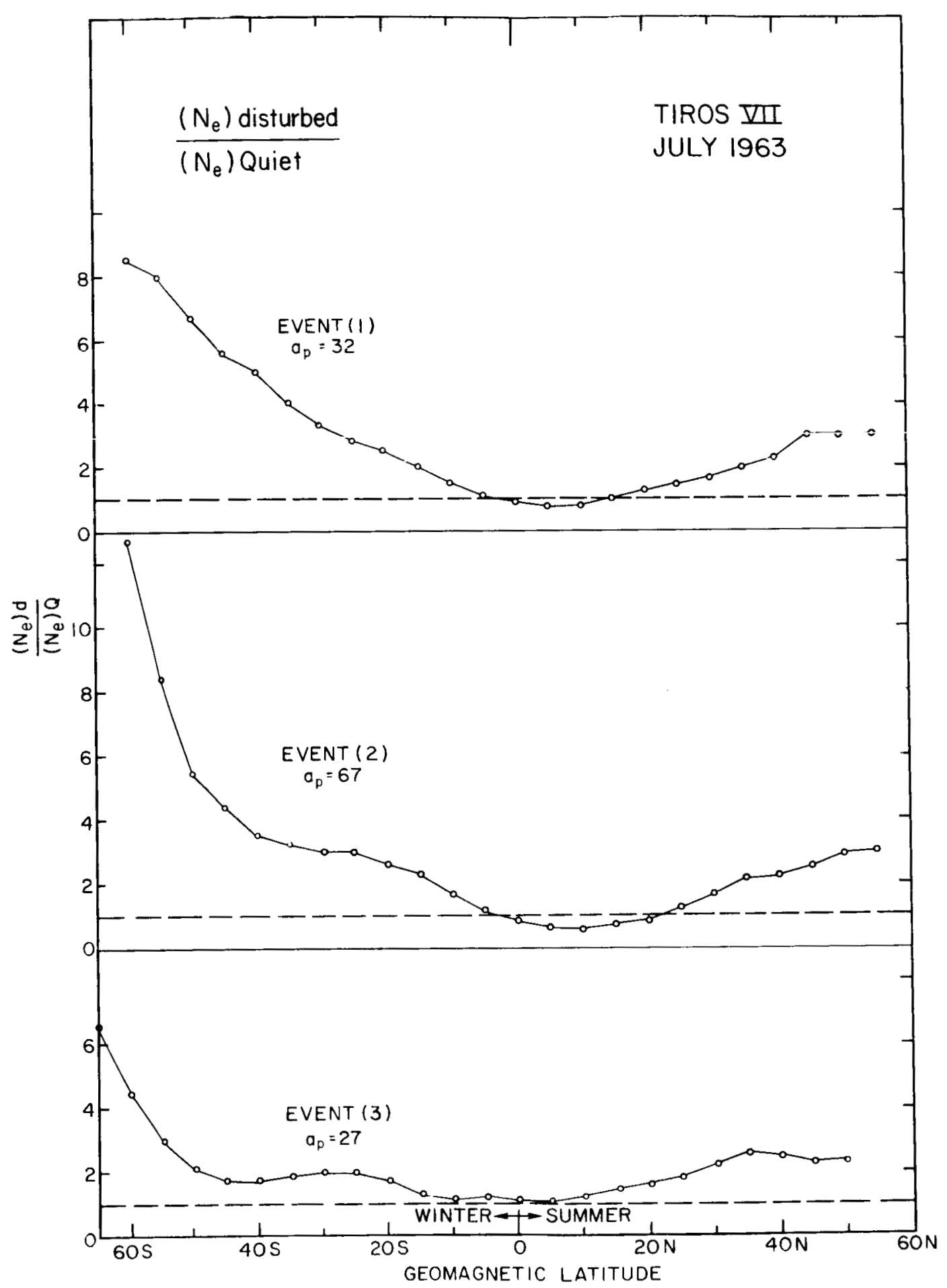

Figure 13. The relative enhancements in $N_{e}$ over the background quiet time distribution is shown for the three events. 
in the winter hemisphere maintains the trend even at $60^{\circ}$, whereas in the summer hemisphere the enhancement appears to level off around $40^{\circ}$ latitude. This results at least in part from the quiet values already being higher in summer hemisphere.

\section{$\underline{\text { Nightside }}$}

The nighttime effects of the same magnetic events were also studied by analyzing the data from the night side of the same orbits. The deviations from the quiet-time behavior were not as remarkable as for the sunlit side, and hence only a single disturbed pass for each event is shown (Figures 14, 15, and 16). The single disturbed pass in each case is the one with maximum deviation from the quiet-time curve, and is in fact a continuation of the most disturbed dayside orbit in each case. A rather surprising feature of the nighttime situation is that the deviations seem to be limited primarily to low and middle latitudes only, contrary to the sunlit side where the high latitudes are most affected. The effects of the milder disturbances (events 1 and 3 ) take the form of a general enhancement except at some middle latitudes for event (3). During the severe storm (event 2) there is a great enhancement of ionization near the equator with little change at all other latitudes. On the dayside the same event produced an enormous enhancement at higher latitudes along with considerabie depression arounu the equator (Figure 11). 


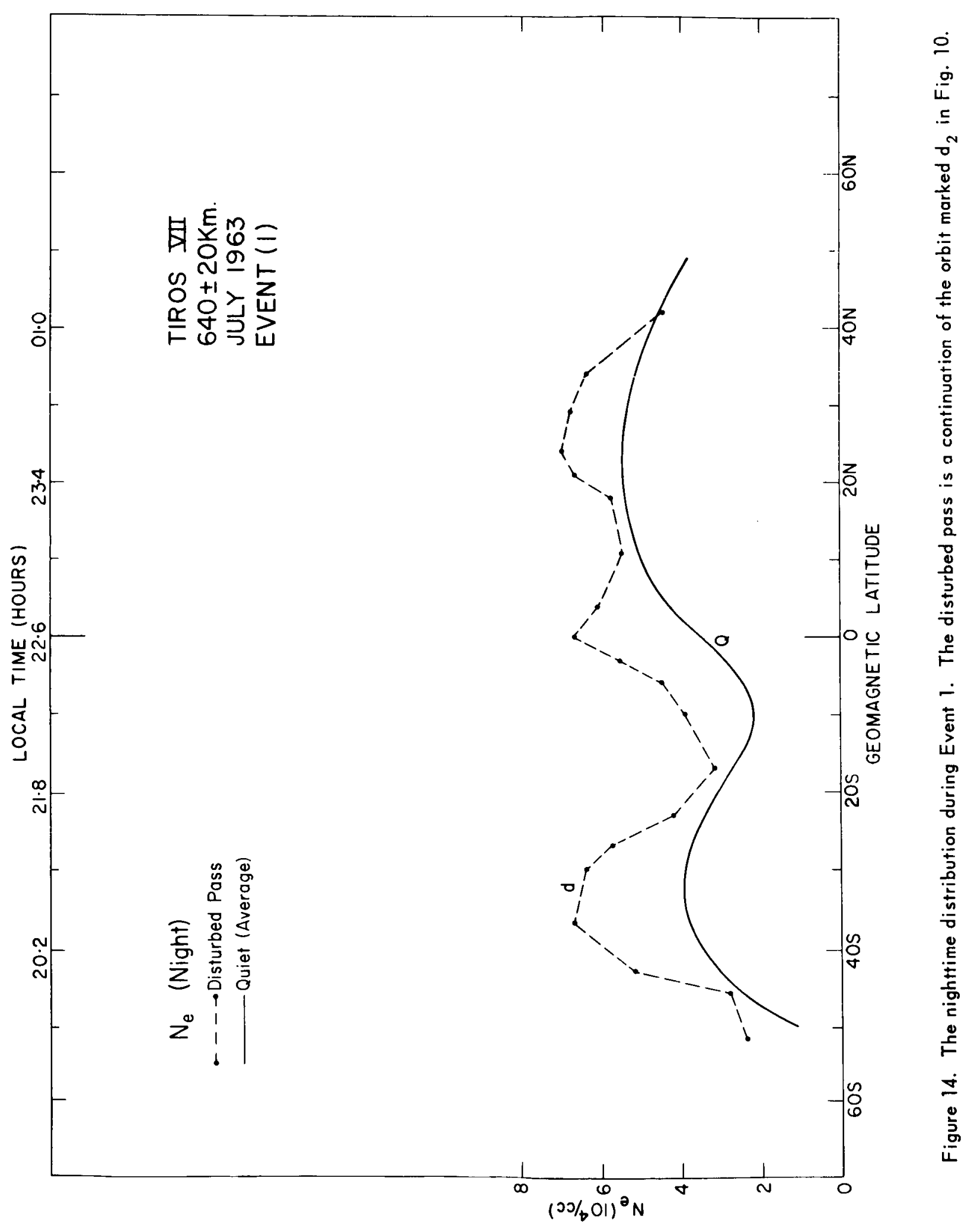




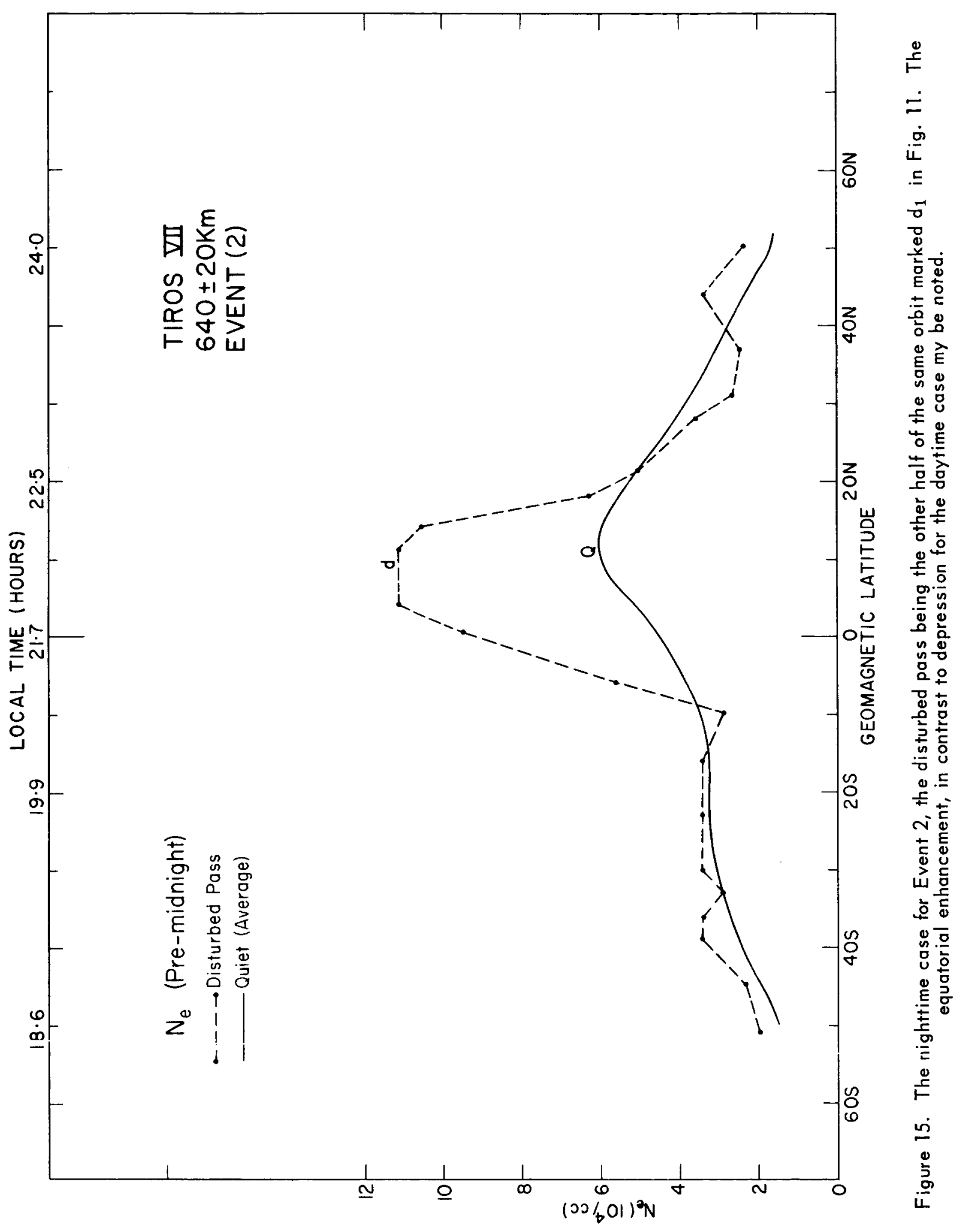




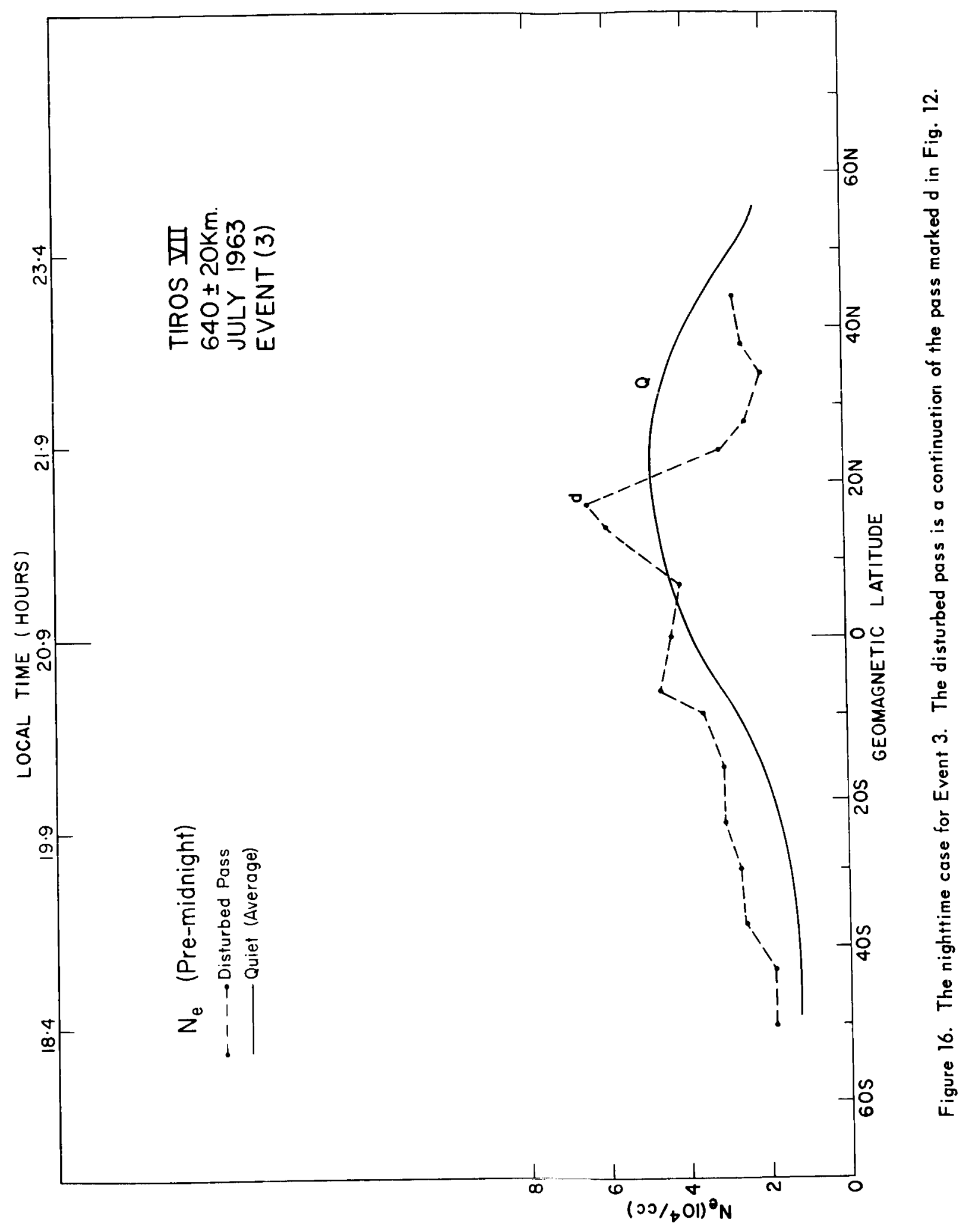




\section{STORM EFFECTS AT 1000 KILOMETERS (EXPLORER XXII):}

Unfortunately, the $1000 \mathrm{~km}$ level could not be studied for the same storms whose results are reported above at $640 \mathrm{~km}$ since Explorer XXII was not yet in orbit. However, Explorer XXII data during February and March of 1965 were used instead. These results have the advantage of simultaneous electron temperature measurements. This particular period was employed because it corresponded to local midday which has been shown to be a fairly stable period in the daytime at that level (Brace, Reddy and Mayr, 1967). The latitudinal distributions of $\mathrm{N}_{e}$ and $\mathrm{T}_{\mathrm{e}}$ are shown in Figures 17 and 18 respectively. The dashed lines labeled D represent the average for many disturbed passes and the solid lines marked $Q$ are for the quiet time. Since no severe storms occurred during this period, it was necessary to make a statistical study of many passes on mildly disturbed days. All the passes with $a_{p}<15$ were classified as quiettime passes and those with $a_{p} \geq 15$ were classified as disturbed. During the entire period of study, $a_{p}$ did not exceed 48 and in fact for most of the disturbed data $a_{p}$ was around 27 . Only the northern hemisphere data are presented since the available southern hemisphere data did not justify a statistical study. For the night side, the departure of the disturbed-time average from the quiet-time average was small in both $\bar{N}_{e}$ and $\bar{T}_{e}$ and are noot of sufficient interest to be shown here. 


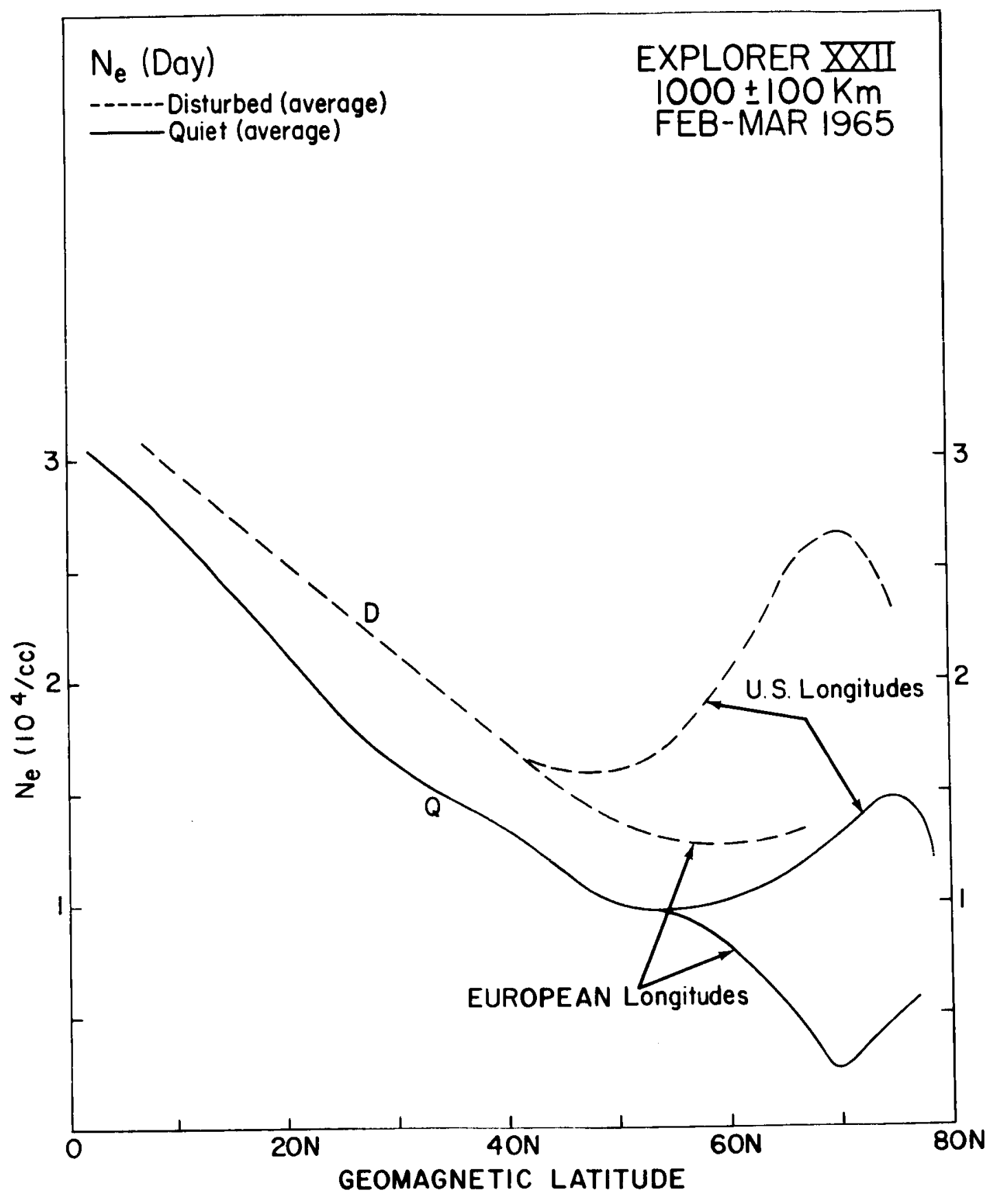

Figure 17. The variations in $N_{e}$ at $1000 \mathrm{~km}$ due to magnetic disturbances. The disturbed-time plot is the average of about 20 Explorer XXII passes when $a_{p}$ varied between 15 and 48. 


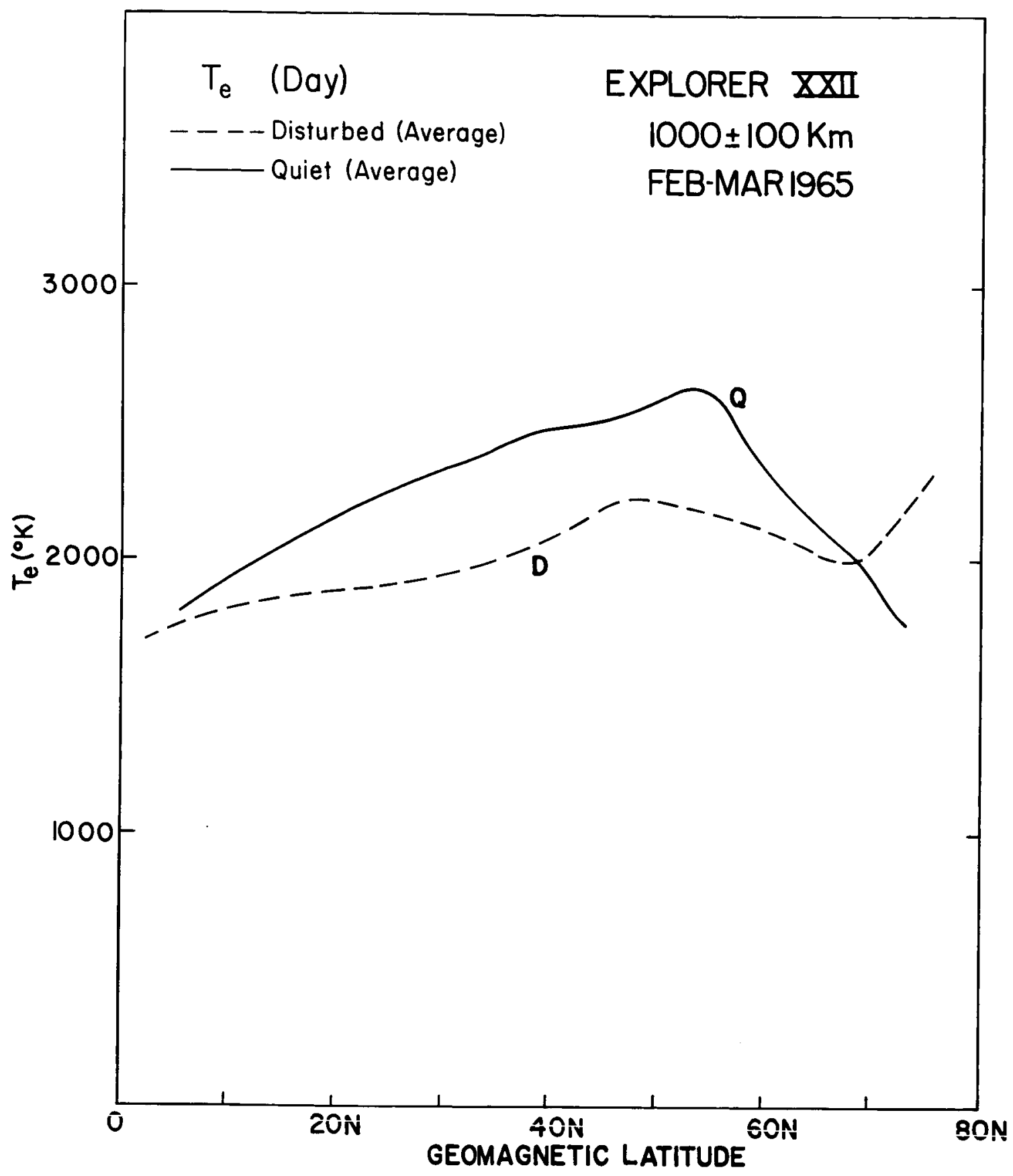

Figure 18. The variations in $T_{e}$ for the same passes as shown in Fig. 17. 
The general enhancement in $\mathrm{N}_{e}$ at $1000 \mathrm{~km}$ is very much less than the enhancement at $640 \mathrm{~km}$, even allowing for the fact that the storms studied (at the $1000 \mathrm{~km}$ level) were mild. The latitudinal distribution of the enhancement appears to be very similar at both the altitudes, the higher latitudes being most affected. The electron temperatures decreased during disturbed periods except at latitudes above $70^{\circ}$ geomagnetic where $\mathrm{T}_{\mathrm{e}}$ increased during storms. It should be mentioned at this point that the changes in $\mathrm{T}_{e}$ or $\mathrm{N}_{e}$ shown in Figures 17 and 18 are well above the measurement accuracy especially since they are averages of many passes.

\section{DISCUSSION OF STORM PHENOMENA}

\section{Bottom Side Behavior:}

Several workers have studied the effects of magnetic storms on the ionosphere, though most of the work has been limited to the bottom side. Matsushita (1959) and Maeda and Sato (1959) have described in detail the effects of storms using data from many locations around the world. A recent survey by Obayashi (1965) cites most of this work and we will limit our discussion to the most pertinent results of these bottomside studies.

During magnetic storms, the peak electron density of the $F_{2}$ layer, $\mathrm{N}_{\mathrm{m}} \mathrm{F}_{2}$, derived from $\mathrm{f}_{\mathrm{o}} \mathrm{F}_{2}$, is known to decrease at middle and high latitudes, while it increases at low latitudes and sometimes at middle latitudes in winter (Obayashi 1964 and the references therein). The height of the $F_{2}$ peak rises in general 
(Matsushita, 1963). Hirao, et al., (1965) have recently reported that the peak $\mathrm{N}_{\mathrm{e}}$ of the nighttime $\mathrm{E}$ region increased with increasing $\mathrm{K}_{\mathrm{p}}$ in the middle latitudes. However, Somayajulu (1963) has shown that the total electron content up to $200 \mathrm{~km}$ is unaffected by storms.

Since the electron loss rate in the $\mathrm{F}_{2}$ region depends on the neutral molecular densities (of $\mathrm{N}_{2}$ and $\mathrm{O}_{2}$ ), the storm time decrease of $\mathrm{N}_{\mathrm{m}} \mathrm{F}_{2}$ was first attributed to the increase in the neutral molecular concentration by Seaton (1956) and was subsequently discussed by several others (Thomas, 1966; Rishbeth, 1964). However, recombination cannot be important at or above $640 \mathrm{~km}$ in spite of an order of magnitude increase in the neutral density.

\section{- Neutral Atmosphere:}

The close correlation between atmospheric neutral density and magnetic activity is well known from the studies of the orbital acceleration of the artificial earth satellites (Jacchia, 1961). A recent analysis by Newton, Horowitz and Priester (1965), using a direct measurement technique, confirms the positive correlation even for very low $\mathrm{K}_{\mathrm{p}}$ values. From measurements of the Explorer IV satellite, Rothwell and McIlwain (1960) reported that the intensity of trapped charged particies decreased above $1000 \mathrm{~km}$ at the fringe of the outer radiation belt during magnetic storms, but increased at lower altitudes beneath the outer zone. To explain this, they replotted the drag data on Explorer IV reported by 
Schilling and Whitney (1959) and showed that the increase in neutral density with $\mathrm{K}_{\mathrm{p}}$ is strongly latitude dependent, being especially large at high latitudes.

The satellite drag data of Jacchia (1959) show that during a storm a very sharp increase in air drag was observed for the $1958 \delta$, whose inclination was $65^{\circ}$, while little or no increase in drag was observed for $1958 \beta$ with a $33^{\circ}$ inclination orbit. This also indicates a strong latitudinal dependence of the neutral density increase during storms. From the results of the atmospheric drag variations of seven satellites whose perigee heights ranged from 205 to $1121 \mathrm{~km}$ reported by Jacchia (1961), it was observed that the neutral density enhancement is greatest at $650 \mathrm{~km}$ and is about seven times the enhancement at $205 \mathrm{~km}$ for a severe storm. The average time lag between the peak in the magnetic disturbance and the peak in atmospheric drag was estimated to be about 6 hours.

From the orbital study of the satellite $1959 \epsilon_{2}$, Groves (1961) expressed the variation of neutral density with $K_{p}$ at $205 \mathrm{~km}$ in the form

$$
\delta=\delta_{0}\left(1+a \mathbf{K}_{\mathbf{p}}\right)
$$

where $\alpha$ is 0.2 for low latitudes and 0.6 for higher latitudes. Thus for a moderate storm $\left(K_{p}=5\right)$, the neutral density at $205 \mathrm{~km}$ might increase by a factor of 4 at higher latitudes. Combining the observations of latitude and altitude behavior of the neutral atmosphere, it is reasonable to conclude that the neutral density at $640 \mathrm{~km}$ increases by more than an order of magnitude at higher latitudes 
for a moderate storm. Since the time scale of drag measurements is of the order of orbits (hours), rapid changes in neutral density cannot be resolved accurately by drag techniques. So the actual increase in neutral density during the storm may be much more than is indicated by drag studies.

\section{Topside Ionosphere:}

Published work on the effects of storms on the topside ionosphere is very limited. Carpenter (1963) indicated that the Knee observed in the whistler studies moved to lower $L$ values with increasing magnetic activity indicating that $\mathrm{N}_{e}$ at very high altitudes decreases. Several workers have reported depression of the total electron content up to the moon, or to several artificial earth satellites during magnetic storms. Combining these results with the changes in the F-region, it was assumed that $\mathrm{N}_{\mathrm{e}}$ decreases at all levels above $200 \mathrm{~km}$ at middle and high latitudes (Obayashi, 1964), in contrast to the results presented here. Cole (1964) theorized that the electrostatic fields associated with geomagnetic fluctuations cause the interchange of tubes of force in the magnetosphere which is equivalent to pumping of plasma from the outer to the inner magnetosphere.

Ariel statellite measurements have provided some indications of the storm effects upon the topside ionosphere. Sayers (1964) reported considerable enhancements of ionization in the topside ionosphere even for very mild disturbances, especially at higher latitudes. Two further reports on Ariel results, one by Willmore and Henderson (1965), and another by Willmore (1964) showed 
convincingly that the $\mathrm{N}_{\mathrm{e}}$ increased during magnetic storms. They also noted that the latitudes of enhancement approach the equator as the storm intensifies and that the enhancements are invariably accompanied by decreases in electron temperature.

The midlatitude electron temperature measurements by the radar backscatter technique (Evans, 1965) suggest that there is little change in the daytime $T_{e}$ with magnetic activity. The change in nighttime was appreciable, $\mathrm{T}_{\mathrm{e}}$ being much higher for the disturbed nights.

In the following section the TIROS VII and Explorer XXII results and the other measurements cited above will be used as the basis for some qualitative suggestions concerning the explanation of the magnetic storm phenomena in the topside ionosphere.

\section{INTERPRETATION}

An explanation of magnetic storm effects in the topside ionosphere must somehow relate the huge high latitude enhancements of the neutral atmospheric density with the similar enhancements of the electron population. The task is complicated by the need to consider dynamic rather than steady state processes to explain the rapid response to the storm. It is not our purpose here to provide a quantitative explanation of these newly discovered storm phenomena. We limit ourselves to a qualitative discussion of a few processes which appear to contribute to the storm time behavior. 
Since the energy content of the neutral atmosphere greatly exceeds that of the charged population, it is most satisfying to explain the storm-time ionosphere behavior in terms of the response of the neutral atmosphere to the disturbance. The neutral density enhancement itself must be caused by some form of heating which is particularly effective at high latitudes. This heating leads to both a hydrostatic (vertical) expansion of the neutral atmosphere as well as to changes in the global pressure gradients and therefore in the neutral wind velocities.

A vertical expansion of the atmosphere would carry the existing ionization upward. During the expansion phase, the upward flux of neutrals could be expected to produce significant drag force upon the ions thus contributing to both the observed upward movement of the $F_{2}$ peak and the enhancement of $N_{e}$ at higher altitudes. The drag force itself is important only near the $F_{2}$ peak where the neutral density is high, however the entire topside ionization which is supported by the F-region is also lifted.

Since the ion drag force is proportional to the relative velocity with which the neutrals move upward through the ions, we can expect the force to be maximum when the rate of expansion is greatest. Therefore the maximum $\mathrm{N}_{e}$ enhancement can be expected to occur before the maximum neutral enhancement, and this is what is actually observed. This, of course, presumes that there are restoring forces on the electron population which return the ionosphere to normal after the neutral expansion has ceased. 
The amount of $\mathrm{N}_{e}$ enhancement which might be expected from the lifting process alone depends very much on the electron scale height at the altitude of observation. For example, in the protonosphere, the scale height is greater than a thousand kilometers, and the lifting which occurs during a storm would produce little enhancement of $\mathrm{N}_{\mathrm{e}}$. Conversely, the enhancement will be large in the upper F-region where the same lifting may be comparable to a scale height. This is in accord with the observations of greater storm-time enhancements at $640 \mathrm{~km}$ than at $1000 \mathrm{~km}$ in the daytime when the $\mathrm{O}^{+}-\mathrm{H}^{+}$transition level lies between these two altitudes (Watt, 1965). Similarly, on the night side of the earth, the transition level decreases to the vicinity of the TIROS orbit thus increasing the scale height. This is consistent with the smaller $N_{e}$ enhancements observed on the nightside of the TIROS orbits.

From the data available, it is not clear whether a storm-time enhancement of the neutral wind system occurs, and if so, whether such an enhancement would produce changes comparable to those induced by the thermal expansion.

There are two ways in which the neutral winds can influence the global distribution of $\mathrm{N}_{\mathrm{e}}$. One is through the neutral-ion drag process described by Kohl and King (1966) which forces ionization to move up or down along the magnetic field. The second effect is to produce a current system such as the electrodynamic drifts described by Martyn (1953), Maeda (1955) and Hirono (1955). The electrodynamic drifts seem to satisfactorily account the storm-time 
behavior of the equatorial region. The vertical drift velocity has quiet and disturbed components which always oppose each other at the equator. The disturbed component, which is upward at night and downward during the day, exceeds the quiet component for a moderate storm. This drift may be responsible for the night-time enhancement and daytime depression in $\mathrm{N}_{e}$ observed at the equator.

At higher latitudes, electrodynamic drifts seem to explain the F-region effects (Maeda, 1963) but are in the wrong sense to account for the observed enhancements at $640 \mathrm{~km}$. At these latitudes thermal expansion and ion drag effects apparently are more important.

\section{Electron Temperature}

The $T_{e}$ results presented here for the $1000 \mathrm{~km}$ level show a small decrease in temperature during storms, except in the polar region (Figure 18). As noted earlier the only other direct measurements of topside $T_{e}$ during storms published so far (Willmore, 1964) indicate that $\mathrm{T}_{\mathrm{e}}$ is reduced throughout the entire altitude range 500 to $1200 \mathrm{~km}$. Willmore attributed this to increased collisional cooling of the electrons subsequent to increased $\mathrm{N}_{e}$.

A second factor which may contribute to the reduced $T_{e}$ during a storm is the escape flux of photoelectrons. It was shown by Hanson (1963) that the escape level for photoelectrons is around $300 \mathrm{~km}$, however this level depends on 
the neutral particle concentrations. Hence, during a storm the change in the escape level for the fast electrons will not be great, since the increase in neutral concentration at $300 \mathrm{~km}$ is observed to be less than the enhancement at $640 \mathrm{~km}$. Assuming that the escape level and the escaping flux do not change, it is obvious that when $\mathrm{N}_{\mathrm{e}}$ increases in the region between the escape level and $640 \mathrm{~km}$, the photoelectron flux arriving at $640 \mathrm{~km}$ would be reduced due to increased Coulomb collisions in the region below. This results in decreased collisional heating of the electrons at $640 \mathrm{~km}$. Though the difference in $\mathrm{T}_{\mathrm{e}}$ and neutral temperature $T_{n}$ decreases during storms and tends to decrease the cooling rate, the enormous increase in neutral concentration more than compensates for this. Thus the decrease in heating and increase in cooling rates combine to produce the observed decrease in $T_{e}$.

It may not be coincidental that $\mathrm{T}_{e}$ increases at latitudes above the main trough and decreases below the trough. This increase in $T_{e}$ at very high latitudes may be due to additional energy of particle precipitation and joule heating. It is interesting to note that the latitude of reversal (Figure 17) from reduced $T_{e}$ to increased $T_{e}$ coincides with the ionization trough reported earlier (Brace and Reddy, 1965; Muldrew, 1965).

\section{CONCLUSIONS}

The quiet-time behavior of the upper ionosphere at $640 \mathrm{~km}$ is very similar to that at $1000 \mathrm{~km}$ reported by Sayers (1964), and Brace and Reddy (1965). The 
high latitude trough in the latitudinal plot of $\mathrm{N}_{\mathrm{e}}$ is a permanent feature of the topside ionosphere at $640 \mathrm{~km}$, as well as at 1000 kilometers, and is especially pronounced at night. The midlatitude maximums in the nighttime latitudinal distribution of $\mathrm{N}_{\mathrm{e}}$ may be explained in terms of an upward drift of ionization during nighttime. This appears to be consistent with the atmospheric wind system suggested by King and Kohl (1965).

Analysis of the storm-time $\mathrm{N}_{e}$ and $\mathrm{T}_{\mathrm{e}}$ data in the topside ionosphere suggests that the neutral atmosphere undergoes thermal expansion and lifts the ionosphere thereby causing enhanced $\mathrm{N}_{\mathrm{e}}$ at middle and high latitudes. The changes in $\mathrm{N}_{e}$ follow the changes in $\mathrm{K}_{\mathrm{p}}$ with a delay of less than 2 hours in contrast to the much longer neutral atmospheric response times estimated from drag data. The daytime ionosphere at $640 \mathrm{~km}$ exhibits much greater response to the storm than the nightside. However, this may be caused by the diurnal variation of the $\mathrm{O}^{+}-\mathrm{H}^{+}$transition level with respect to the fixed altitude of the satellite.

The storm time enhancement of $\mathrm{N}_{e}$ usually is accompanied by a reduction in $T_{e}$, at least at $1000 \mathrm{~km}$ where simultaneous $\mathrm{N}_{e}$ and $\mathrm{T}_{\mathrm{e}}$ data were available. This is consistent with decreased fast electron heating and increased collisional cooling. At latitudes above $60^{\circ}$ however, both $\mathrm{N}_{e}$ and $\mathrm{T}_{e}$ are increased indicating a definite increase in the energy input. 


\section{APPENDIX}

\section{THE SYSTEM}

The 300 pound TIROS VII satellite, having the shape of a hatbox 42 inches in diameter and 22.5 inches high, is shown in Figure 19. Prominent external features of the satellite include the $\mathrm{T}-\mathrm{V}$ lenses, command and telemetry antennas, and the electrostatic probe. The sides and top of the hat carried solar cells to provide for the satellite power requirements. Surface area not covered by solar cells was aluminum, treated to maintain surface conductivity. In addition to the television subsystem, other equipment included infrared heat mapping experiments and the cylindrical electrostatic probe experiment. A photograph of the probe experiment is shown in Figure 20. The sensor and the electronics were connected through a shielded cable as shown.

The spacecraft telemetry and spin rate imposed limitations on the sweep rate and current range switching of the experiment. The spin period was 12 seconds, and to assure non-wake measurements during each satellite rotation, a sweep period of 2 seconds was selected. The infrared and electrostatic probe experiments time-shared a subcarrier oscillator, with a frequency band of $456 \mathrm{hz} \pm 27 \mathrm{hz}$, giving a probe data duty cycle of 18 seconds on, 12 seconds off (see Figure 21). The output of the subcarrier oscillator was played into the onboard tape recorder over an entire orbit, then played back on command at a rate 30 times the recorded rate as the spacecraft passed over an appropriate ground station. These factors resulted in a relatively low information rate. The 


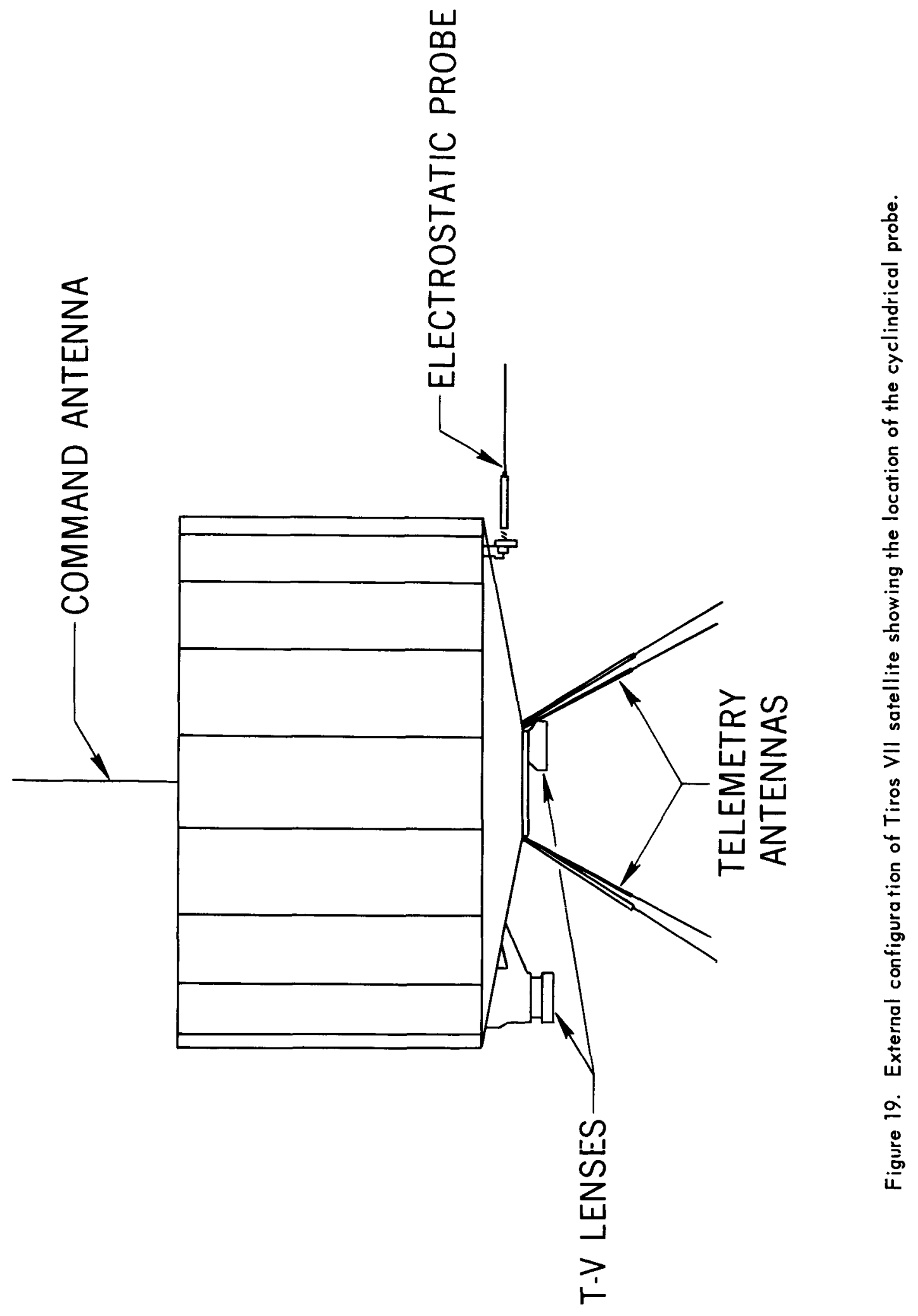




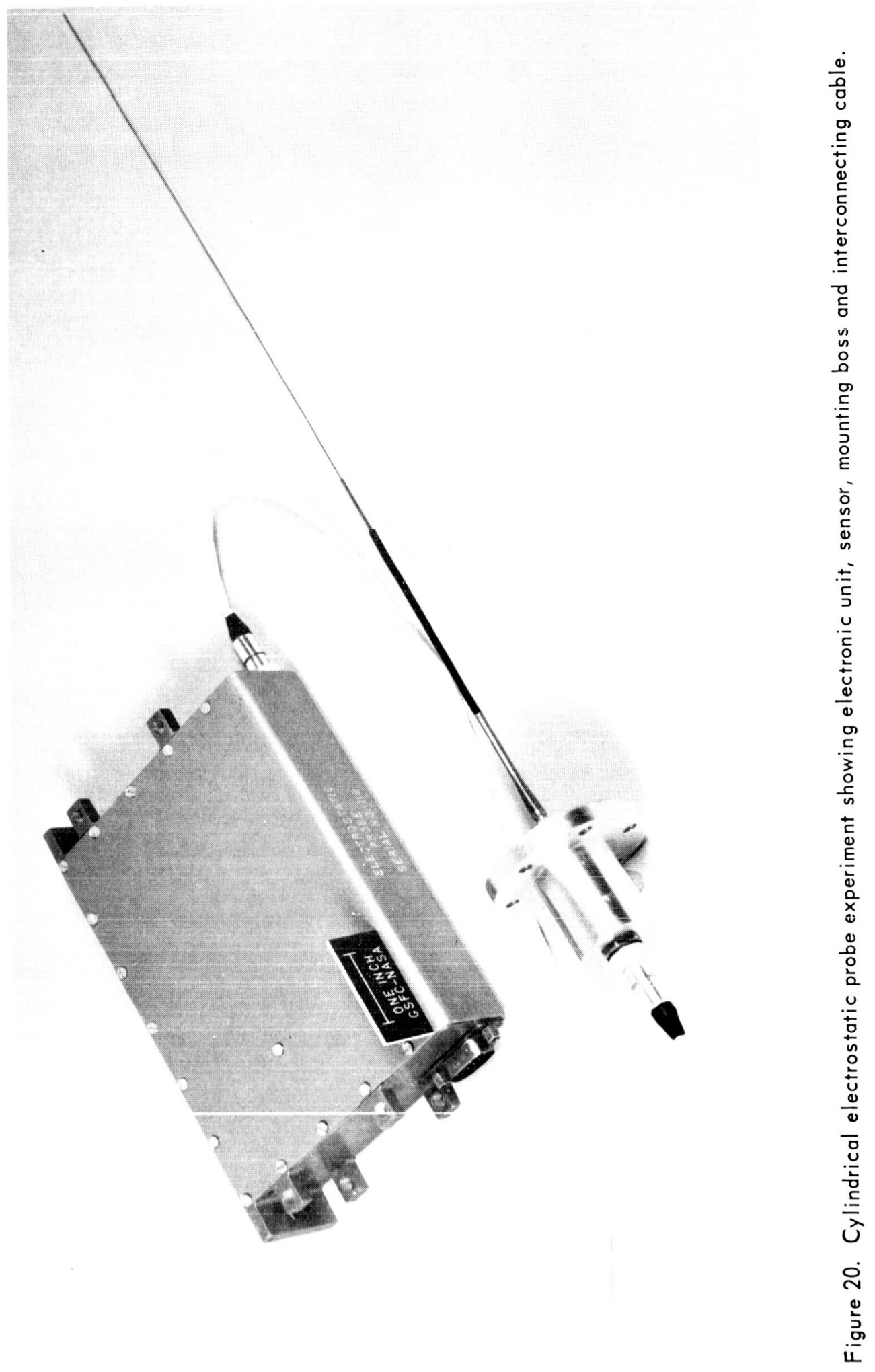




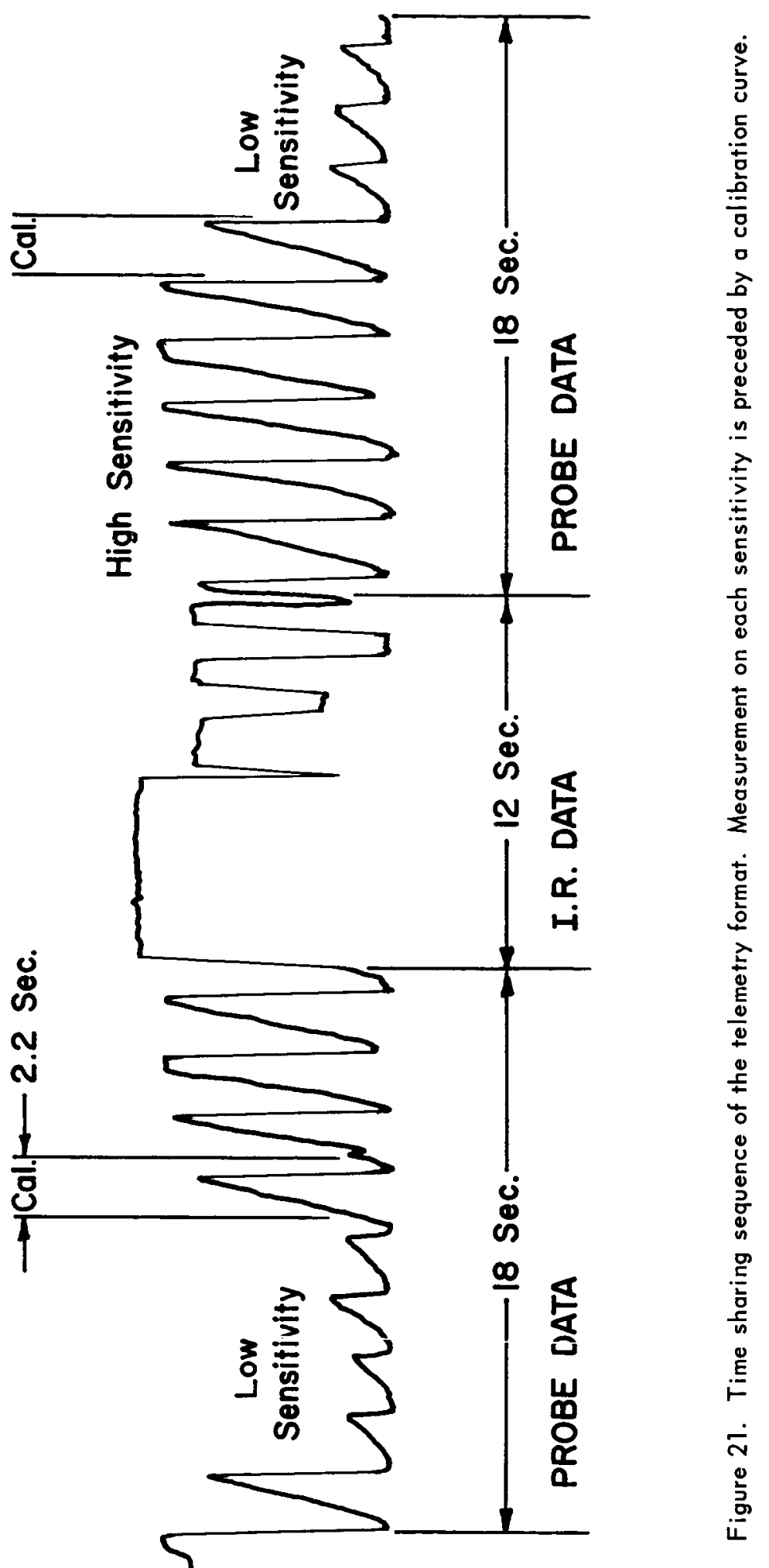


consequent compromise in data resolution made production processing of the data for electron temperature impractical.

The electrostatic probe experiment made direct measurements of electron density of the ionosphere in the immediate vicinity of the satellite. This was done by measuring the current collected by the cylindrical probe extended from the surface of the satellite as the voltage applied to the probe was varied. To avoid possible disturbing effects of any electrostatic sheath about the satellite the collector was isolated by use of a guard electrode which was driven at the same potential as the collector. The conducting satellite surface provided approximately 2000 square inches of reference area against which the experiment collector was driven. This provided a reference to collection area ratio of about 500. The applied voltage was in the form of a linear ramp of 0 to +1.5 volts, each sweep preceded by a short region of zero voltage.

The actual probe voltage $\mathrm{V}$ with respect to the plasma is the difference between the applied voltage $\mathrm{V}_{\mathrm{a}}$ and the satellite potential $\mathrm{V}_{\mathrm{s}}$ :

$$
\mathrm{V}=\mathrm{v}_{\mathrm{a}}-\mathrm{v}_{\mathrm{s}}
$$

The satellite potential was usually about -0.5 volts. Thus $\mathrm{V}$ varied from about -0.5 volts (sufficient to repell most of the thermal electrons) to about +1 volt at the maximum applied voltage $\mathrm{V}_{\mathrm{a}_{\max }}$ (sufficient to considerably accelerate electron flow to the probe). 
The theory of collection of current by plasma probes has been studied extensively, and volt ampere characteristics have been derived for the three simple geometries: a plane, a sphere and a cylinder (Mottsmith and Langmuir, 1926). Theoretically, a volt ampere characteristic for a small cylinder may be divided into three distinct regions (Figure 22). The region to the left, where the electron current is negligible is referred to as the ion saturation region. Between this region and the plasma potential $\left(V_{p}\right.$ on the figure) the electron current varies exponentially with voltage. This region is referred to as the electron retardation region. With sufficient data resolution, the electron temperature can be derived from the slope of the logarithm of this current. As suggested earlier, TIROS VII data resolution was marginal in this respect due to the low information rate of the subcarrier and compounded by the "wow and flutter" introduced by the tape recorder. To the right, i.e. the positive voltage side of the plasma potential, is the electron saturation region where the ion current is negligible, and for practical purposes the current is all electron current. The electron current in this region is approximated by the expression (Spencer et al., 1965):

$$
\mathrm{I}_{\mathrm{e}}=\frac{\mathrm{AN}_{\mathrm{e}} \mathrm{e}}{\pi}\left(\frac{2 \mathrm{eV}}{\mathrm{m}_{\mathrm{e}}}\right)^{1 / 2},\left|\frac{\mathrm{eV}}{\mathrm{kT}_{\mathrm{e}}}\right|>>1
$$

where $I_{e}$ is the collected current, $A$ is the probe area, $N_{e}$ the electron number density, e the electron charge, $\mathrm{m}_{\mathrm{e}}$ the electron mass, $\mathrm{k}$ is Boltzmann constant, $\mathrm{V}$ is the probe voltage with respect to the plasma, and $\mathrm{T}_{\mathrm{e}}$ is the electron temperature. It is important to note that the electron saturation current is independent of electron 


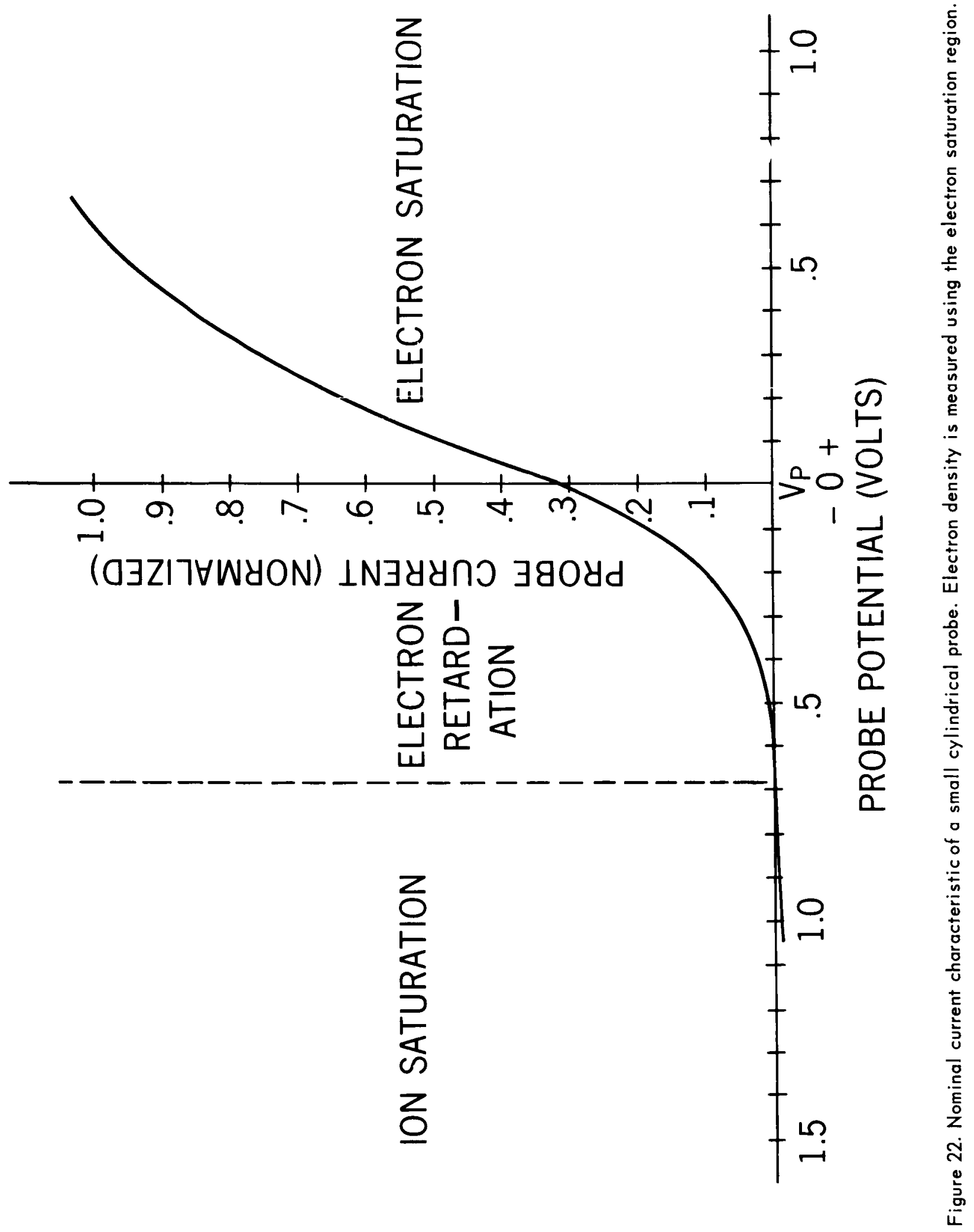


temperature and therefore the electron density can be derived directly from the measured current. It should also be noted that an uncertainty in $\mathrm{V}$ will result in some error in the measurement of $\mathrm{N}_{\mathrm{e}}$. The value used in data reduction was $\left(V_{a_{\max }}-V_{s}\right)$. This value was usually between 0.7 and 1.0 volt, the variation arising from changes in $V_{s}$ due to such things as induced voltages as well as variations in photo emission current due to solar ultraviolet radiation. The value of $\mathrm{V}_{\mathrm{s}}$ was determined from the current characteristics with an accuracy of about a tenth of a volt and it was observed that the variations within any single orbit were normally less than one tenth of a volt. The measurement error due to the uncertainty in $\mathrm{V}$ is less than $10 \%$ for the data presented here.

The effect of satellite motion through the medium required some consideration. While electron velocities are many times the satellite velocity and no correction for velocity effect in the volt ampere characteristics (equation 4) is necessary, ion velocities are usually considerably less than that of the satellite. This produces an ion wake behind the satellite, and since there are fewer positive ions, an electron wake also exists because of space charge effect. Volt ampere characteristics taken in the wake are often distorted and may lead to erroneous values of $\mathrm{N}_{\mathrm{e}}$. Wake characteristics are easily recognized however, as shown in Figure 23, and only non-wake data are used for electron density measuremenis.

\section{THE SENSOR}

A cylindrical sensor of the type employed in the TIROS VII experiment is pictured in Figure 24. The assembly consists of two concentric electrodes 


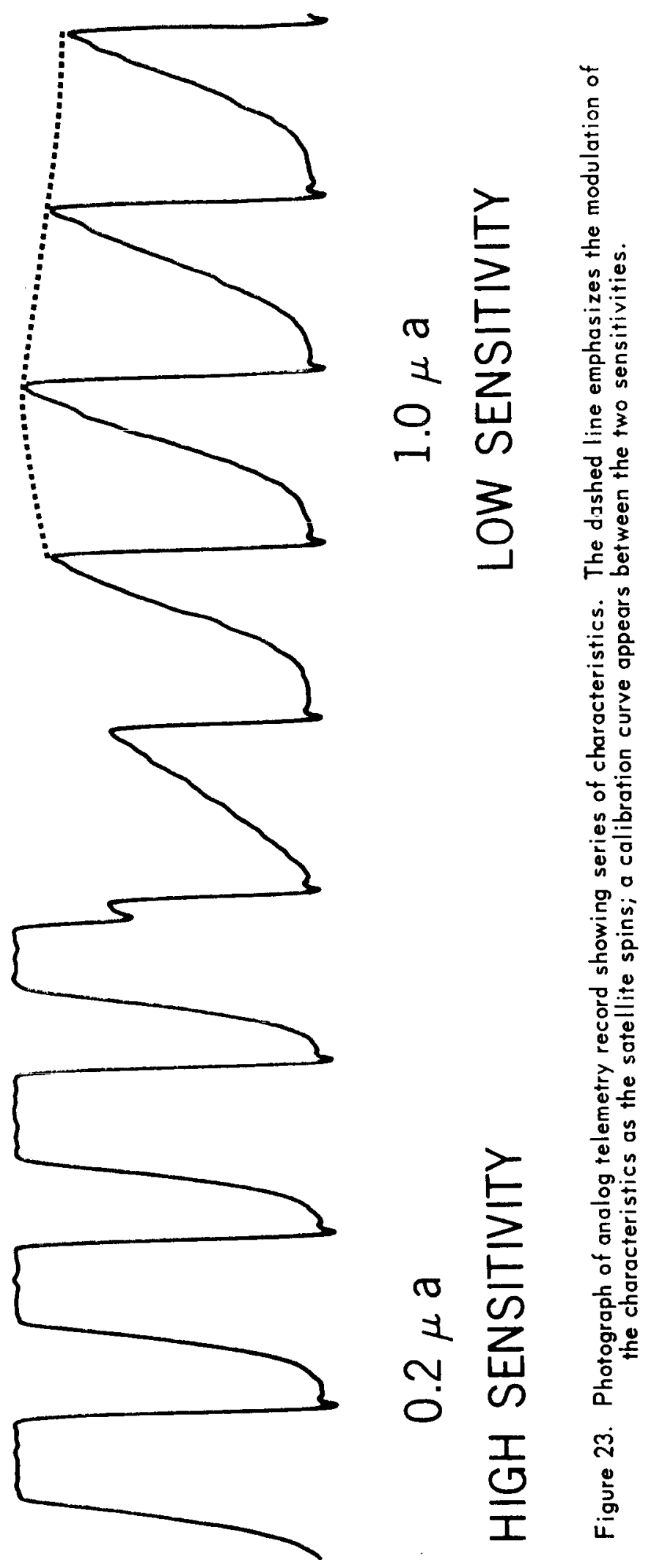




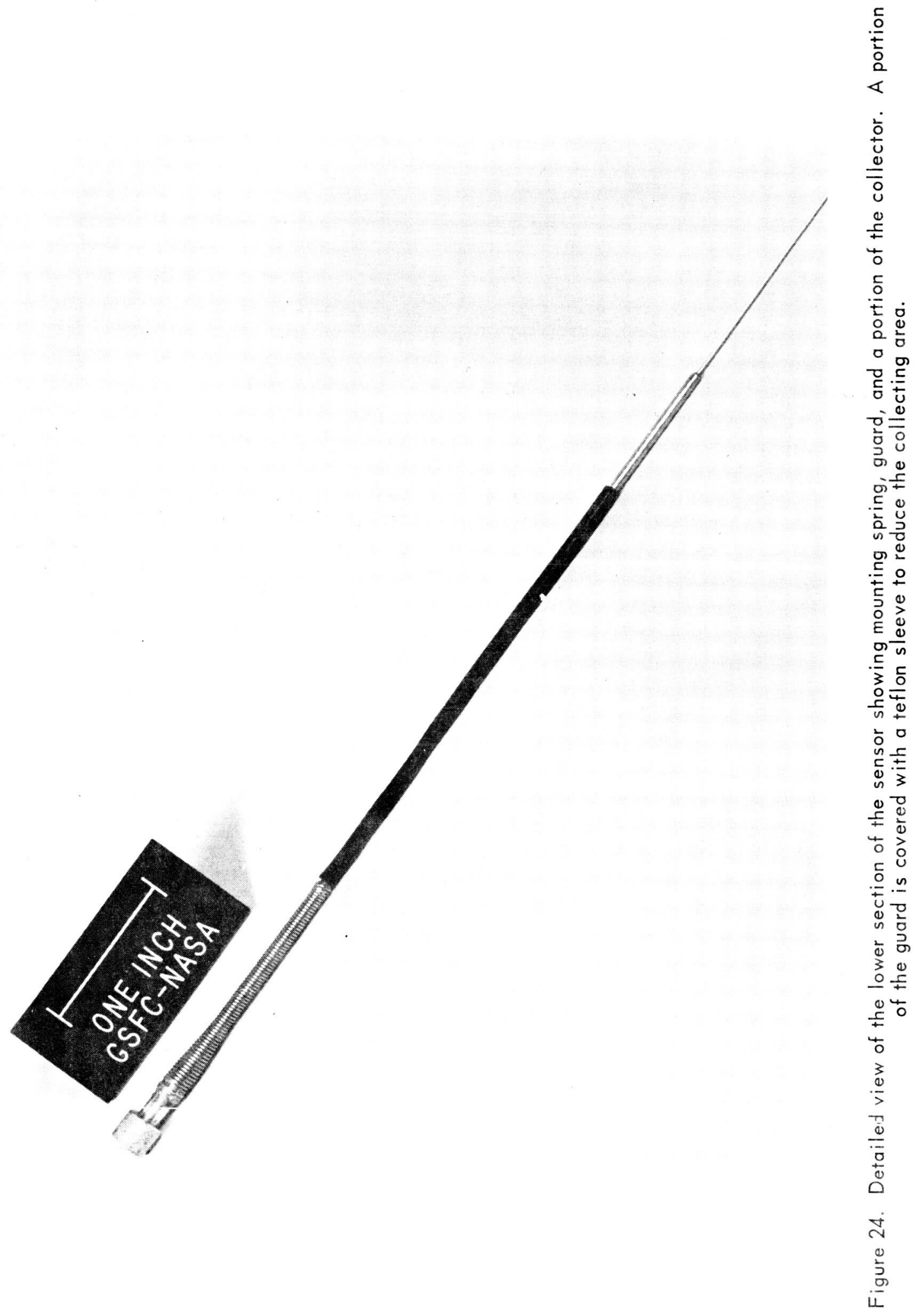


which are spring-mounted to a coaxial connector. The inner electrode, employed as the collector, extends $23 \mathrm{~cm}$ beyond the outer electrode, which acts both as a guard to minimize the effects of fringe fields and as a spacer to separate the collector from the vehicle. The diameter of the collector is $0.057 \mathrm{~cm}$ and the guard length and diameter are $10 \mathrm{~cm}$ and $0.168 \mathrm{~cm}$, respectively. A teflon insulating tube covers the guard to within $2.2 \mathrm{~cm}$ of the collector to reduce the sensor area and thus improve the reference-to-sensor area ratio. The concentric coil springs, which support the collector and provide electrical connection, are $3.25 \mathrm{~cm}$ long and are insulated from each other by a flexible woven glass sheath. The springs are required to permit the probe to fit within the rocket shroud during launch and then extend into the plasma when the shroud is ejected. The total length of the guard including the spring and connector is $14.5 \mathrm{~cm}$.

The length and diameter of the collector provided a length to diameter ratio sufficiently great to insure orbital-motion-limited operation according to the theory for a small cylinder at the densities anticipated in the TIROS VII orbit.

\section{THE ELECTRONICS}

Figure 25 is a functional block diagram of the complete experiment. In addition to the sensor described above, an electronics unit within the satellite included a DC-DC converter, a waveform generator, current detector, amplifier, and circuits for timing, current sensitivity switching and calibration. The experiment 


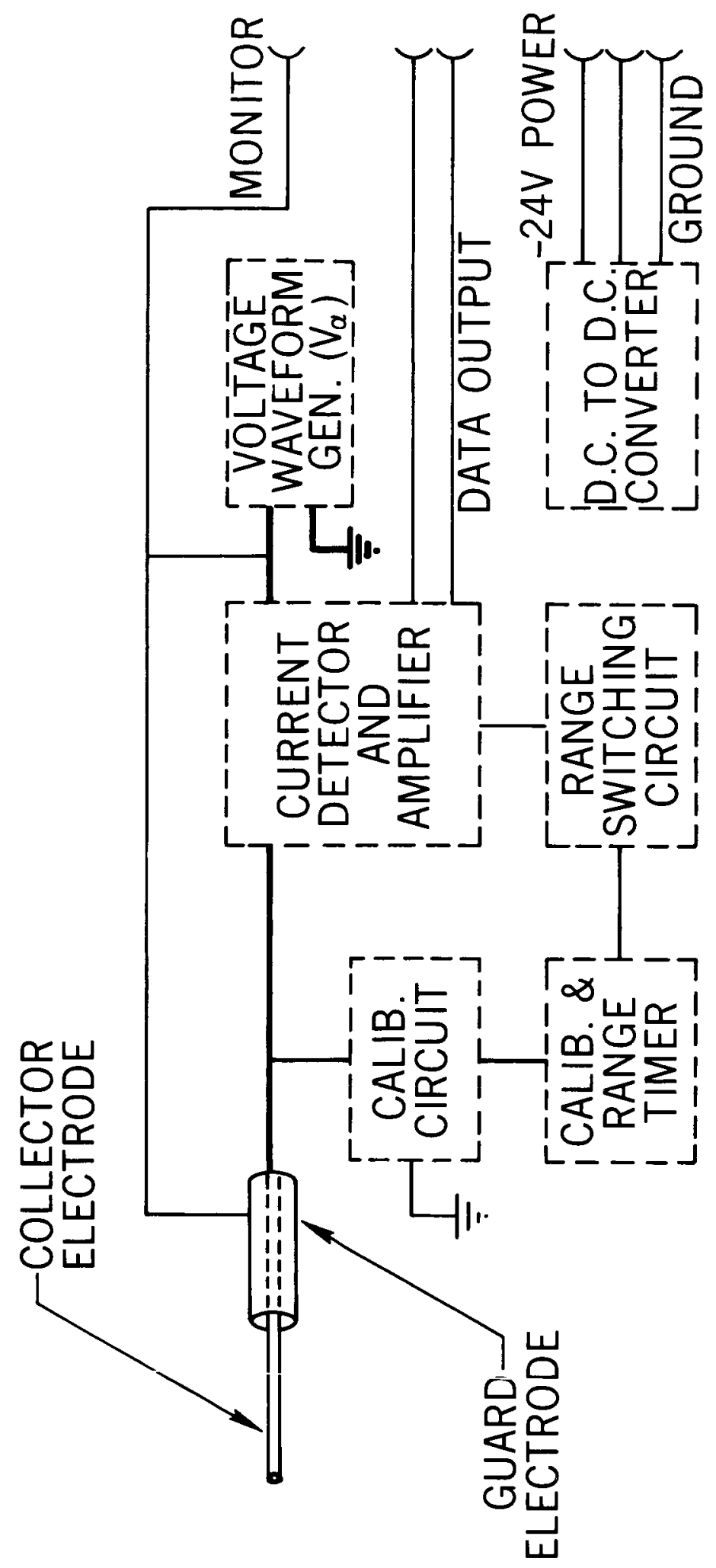

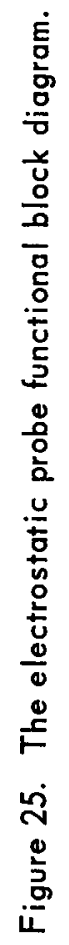


was essentially self contained, requiring only power input and signal output leads, although several test points were brought out to the interface connector for convenience in prelaunch checkouts.

In operation, the linear sawtooth voltage is applied to the collector through a ring bridge type current detector. The resultant current flow is thus converted to an a.c. signal at the amplifier input. This signal is amplified and rectified so that the output is a d.c. voltagc directly proportionai to the input current. As a result of the transformer coupled input from the ring bridge modulator the amplifier output has the same polarity for both positive and negative inputs. In addition, as a result of rectification, the output characteristic is slightly nonlinear near zero. Because the ion currents were negligibly small the modulator input was simply biased slightly positive to avoid operation in the nonlinear region of the amplifier (see Figure 26). The short flat region in the applied voltage wave-form provided a reference level to aid in data reduction. The output from the demodulator was a 0 to 8 volt signal which was fed directly to the voltage controlled oscillator in the telemetry system. The input current sensitivity was alternated between $2.5 \times 10^{-8}$ ampere per volt output and $1.25 \times 10^{-7}$ ampere per volt output. This corresponds to approximately $2 \times 10^{-7}$ ampere full scale and $1 \times 10^{-6}$ ampere full scale respectively. Range switching was accomplished at 10.5 second intervals by switching between shunt resistors across the ring bridge modulator. At the beginning of each range period an endto-end current calibration was accomplished by disconnecting the collector and 


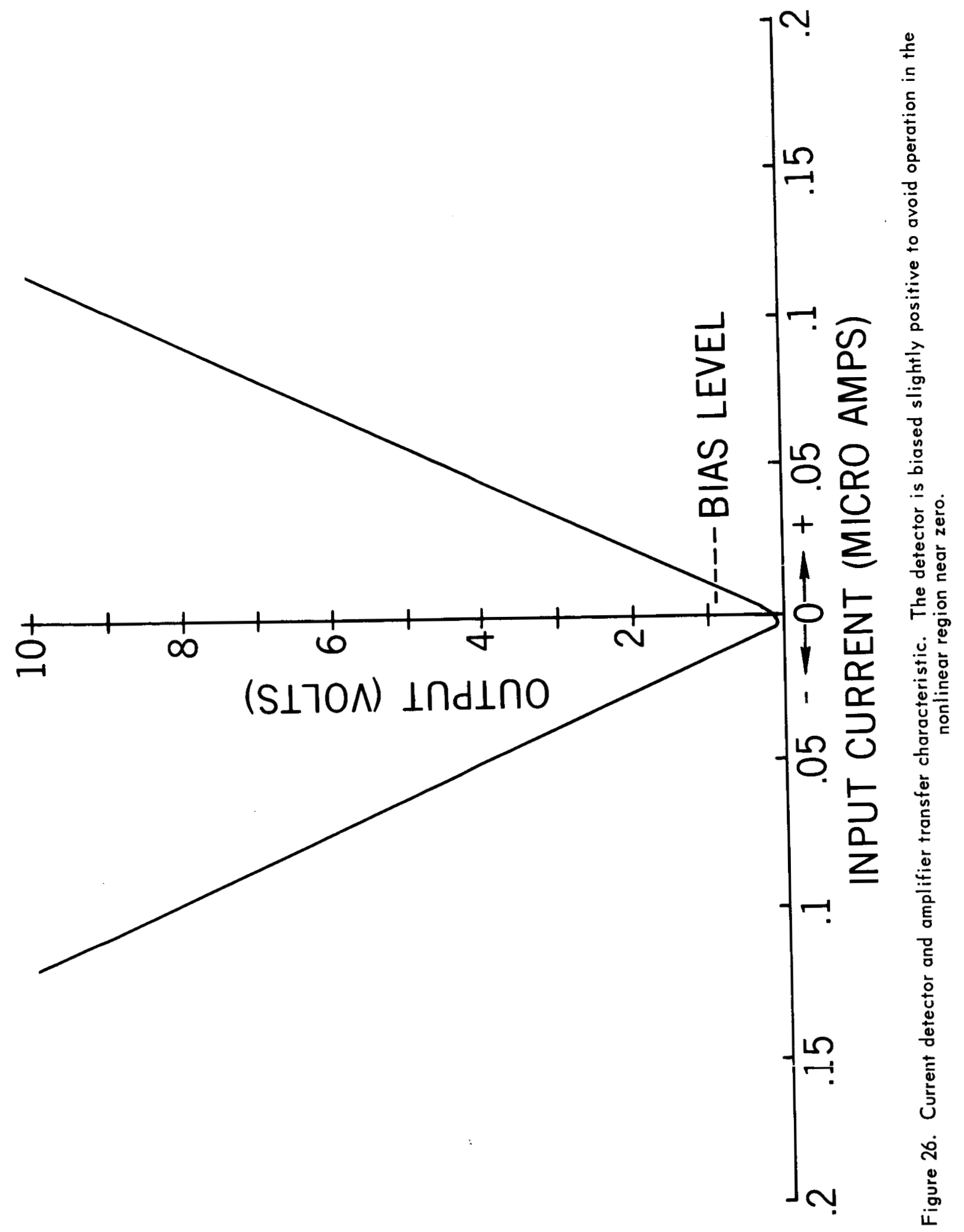


substituting a known resistance for approximately one sawtooth period. The experiment hardware weighed approximately 1.5 pounds and required 1.4 watts of power.

\section{ACKNOWLEDGMENTS}

Our thanks are due to Tuck Bin Lee of the University of Michigan for the development of the electronic system and to Fred Huie and Joseph Johnston for the analysis of the data. We thank J. H. Sayler and G.S. Dunham for programming the data reduction, and H. G. Mayr for the helpful discussions. We also thank J. W. King of the Radio and Space Research Station, England for his valuable comments. During the progress of this work, one of the authors (B.M. Reddy) was an NAS-NRC post-doctoral resident research associate. 


\section{REFERENCES}

B̈race, L. H., and B. M. Reddy, Early electrostatic probe results from Explorer 22 , J. Geophys. Res., 70, 5783-5792, 1965.

Brace, L. H., B. M. Reddy, and H. G. Mayr, Global behavior of the ionosphere at 1000 kilometers altitude, J. Geophys. Res., 72, Jan. 1, 1967.

Brace, L. H., N. W. Spencer, and A. Dalgarno, Detailed behavior of the midlatitude F-region from Explorer 17 satellite, Planet. Space Sci., 13, 647-666, 1965.

Carpenter, D. L., Whistler evidence of a knee in the magnetosphere ionization density profile, J. Geophys. Res., 68, 1675-1682, 1963.

Chan, K. L., L. Colin, and J. O. Thomas, Electron densities and scale heights in the topside ionosphere, Vol. II, NASA SP-3032, 1966.

Cole, K. D., On the depletion of ionization in the outer magnetosphere during magnetic disturbances, J. Geophys. Res., 69, 3595-3601, 1964.

Evans, J. V., Midlatitude ionospheric temepratures on magnetically quiet and disturbed days, J. Geophys. Res., 70, 2726-273̄̄, $196 \overline{5}$.

Groves, G. V., Correlation of upper atmosphere air density with geomagnetic activity, November 1960, Space Res., II, 751-753, 1961. 
Hanson, W. B., Electron temperatures in the upper atmosphere, Space Res., $\underline{3}$, $282-302,1963$.

Hanson, W. B., and T. N. L. Patterson, The maintenance of the night-time Flayer, Planet. Space Sci., 12, 979-997, 1964.

Hirao, K., N. Wakai, K. Sawada, T. Hikosaka, K. Yano, and K. Maeda, Some evidences of the particle effects on the ionosphere at middle latitudes, Space Res., $\underline{\text { V }, 1058-1070, ~} 1965$.

Hirono, M., Effect of gravity and ionization pressure gradient on the vertical drift in the $\mathrm{F}_{2}$ region, Rep. Ionos. Res. Japan, 9, 95-104, 1955.

Jacchia, L. G., Corpuscular radiation and the acceleration of artificial satellites, Nature, 183, 1662-1663, 1959.

Jacchia, L. G., Satellite drag during the events of November 1960, Space Res., II, $747-750,1961$.

King, J. W., and H. Kohl, Upper atmospheric winds and ionospheric drifts caused by neutral air pressure gradients, Nature, 206, 699-701, 1965.

Kohl, H., and J. W. King, Atmospheric winds between 100 and $700 \mathrm{~km}$ and their effects on the ionosphere, Report distributed at the URSI Assembly Meeting, Munich, September 1966. 
Lockwood, G. E. K., and G. L. Nelms, Topside sounder observations of the equatorial anomaly in the $75^{\circ} \mathrm{W}$ longitude zone, J. Atmospheric Terrest. Phys., $\underline{26}, 569-580,1964$.

Maeda, H., Worldwide patterns of ionization drifts in the ionospheric F-region as deduced from geomagnetic variations, Proc. Int. Conf. The Ionosphere, Inst. Phys. Soc., London, 187-190, 1963.

Maeda, K., Theoretical study on the geomagnetic distortion in the $F_{2}$ layer, Rep. Ionos. Res. Japan, $\underline{9}, 71-85,1955$.

Maeda, K., and T. Sato, The F-region during magnetic storms, Proc. Inst. Radio Eng., 4 $\underline{47}, 232-238,1959$.

Martyn, D. F., The morphology of ionospheric variations associated with magnetic disturbances, Proc. Roy. Soc. A., 218, 1-18, 1953.

Matsushita, S., A study of the morphology of ionospheric storms, J. Geophys. Res., $\underline{64}, 305-321,1959$.

Matsushita, S., Ionospheric variations during geomagnetic storms, Proc. Int. Conf. The Ionosphere, 120-127, 1963.

Mayr, H. G., L. H. Brace, and Dunham, On the ion composition and temperature in the topside ionosphere, NASA X-621-66-573, 1966. 
Mottsmith, H. M., and I. Langmuir, The theory of collectors in gaseous discharges, Phys. Rev., 28, 727-763, 1926.

Muldrew, D. B., F-layer ionization troughs deduced from aloutte data, J. Geophys. Res., 70, 2635-2650, 1965.

Newton, G. P., R. Horowitz, and W. Priester, Atmospheric density and tcmpcrature variations from the Explorer XVII satellite and a further comparison with satellitc drag, Planet. Space Sci., 13, 599-616, 1965.

Obayashi, T., Morphology of storms in the ionosphere, Research in Geophysics (edited by H. Odishaw) Vol. I, 335-336, 1964.

Rishbeth, H., A time-varying model of the ionospheric $F_{2}$ layer, J. Atmospheric Terrest. Phys., 26, 657-685, 1964.

Rothwell, P., and C. E. McIlwain, Magnetic storms and the VanAllen Radiation Belts - observations from satellite $\underline{1958 \epsilon}$ (Explorer IV), J. Geophys. Res., $\underline{65}$, $799-806,1960$.

Sayers, J., The electron density distribution in the topside ionosphere, 1, Magnetic-field-aligned strata, Proc. Roy. Soc. London, A, 281, 450-458, 1964.

Schilling, G. F., and C. A. Whitney, Derivation and analysis of atmospheric

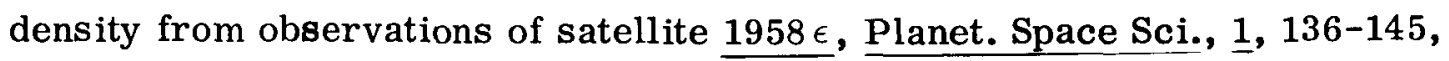
1959. 
Seaton, M. J., A possible explanation of the drop in F-region critical densities accompanying major ionospheric storms, J. Atmospheric Terrest. Phys., $\underline{8}$, 122-123, 1956.

Somayajulu, Y. V., Changes in the F-region during magnetic storms, J. Geophys.

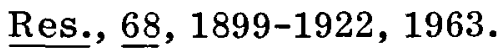

Spencer, N. W., L. H. Brace, G. R. Carignan, D. R. Taeusch, and H. Niemann, Electron and moelcular nitrogen temperature and density in the thermosphere, J. Geophys. Res., 70, 2665-2698, 1965.

Thomas, L., Electron density distributions in the daytime $\mathrm{F}_{2}$ layer and their dependence on neutral gas, ion, and electron temperatures, J. Geophys. Res., $\underline{71}, 1357-1366,1966$.

Watt, T. M., Ion distribution and temperature in the topside ionosphere obtained from the Alouette satellite, J. Geophys. Res., 70, 5849-5859, 1965.

Willmore, A. P., Geographical and solar activity variations in the electron temperature of the upper F-region, Proc. Roy. Soc. London, A, 286, 537-558, 1964.

Willmore, A. P., and C. L. Henderson, Magnetic shell enhancements during magnetic disturbances, Space Res. $\underline{\text { V }}$ 241-249, 1965. 